\title{
Isotopic ratios of $\mathrm{H}, \mathrm{C}, \mathrm{N}, \mathrm{O}$, and $\mathrm{S}$ in comets $\mathrm{C} / 2012 \mathrm{F6}$ (Lemmon)

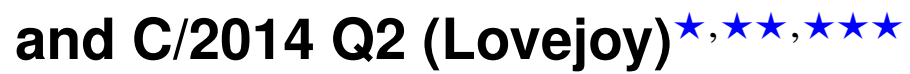

\author{
N. Biver ${ }^{1}$, R. Moreno ${ }^{1}$, D. Bockelée-Morvan ${ }^{1}$, Aa. Sandqvist ${ }^{2}$, P. Colom ${ }^{1}$, J. Crovisier ${ }^{1}$, D. C. Lis ${ }^{3}$, J. Boissier ${ }^{4}$,

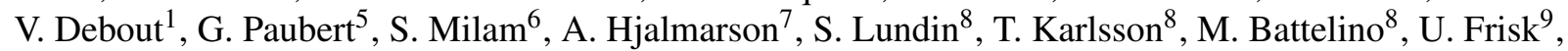 \\ D. Murtagh ${ }^{10}$, and the Odin team. \\ ${ }^{1}$ LESIA, Observatoire de Paris, PSL Research University, CNRS, Sorbonne Universités, UPMC Univ. Paris 06, Univ. Paris Diderot, \\ Sorbonne Paris Cité, 5 place Jules Janssen, 92195 Meudon, France \\ e-mail: nicolas.biver@obspm.fr \\ 2 Stockholm Observatory, AlbaNova University Center, 10691 Stockholm, Sweden \\ 3 LERMA, Observatoire de Paris, PSL Research University, CNRS, Sorbonne Universités, UPMC Univ. Paris 06, 75014 Paris, \\ France \\ ${ }^{4}$ IRAM, 300, rue de la Piscine, 38406 Saint-Martin-d'Hères, France \\ 5 IRAM, Avd. Divina Pastora, 7, 18012 Granada, Spain \\ ${ }^{6}$ NASA Goddard Space Flight Center, Astrochemistry Laboratory, Code 691.0, Greenbelt, MD 20771, USA \\ 7 Onsala Space Observatory, Chalmers University of Technology, 43992 ONSALA, Sweden \\ 8 OHB Sweden, PO Box 1269, 16429 Kista, Sweden \\ 9 Omnisys Instruments, August Barks Gata 6B, 42132 Västra Frölunda, Sweden \\ 10 Dept. of Radio and Space Science, Chalmers Technical University, 41258 Gothenburg, Sweden
}

Received 24 December 2015 / Accepted 4 March 2016

\begin{abstract}
The apparition of bright comets C/2012 F6 (Lemmon) and C/2014 Q2 (Lovejoy) in March-April 2013 and January 2015, combined with the improved observational capabilities of submillimeter facilities, offered an opportunity to carry out sensitive compositional and isotopic studies of the volatiles in their coma. We observed comet Lovejoy with the IRAM $30 \mathrm{~m}$ telescope between 13 and 26 January 2015, and with the Odin submillimeter space observatory on 29 January-3 February 2015. We detected 22 molecules and several isotopologues. The $\mathrm{H}_{2}^{16} \mathrm{O}$ and $\mathrm{H}_{2}^{18} \mathrm{O}$ production rates measured with Odin follow a periodic pattern with a period of 0.94 days and an amplitude of $\sim 25 \%$. The inferred isotope ratios in comet Lovejoy are ${ }^{16} \mathrm{O} /{ }^{18} \mathrm{O}=499 \pm 24$ and $D / H=1.4 \pm 0.4 \times 10^{-4}$ in water, ${ }^{32} \mathrm{~S} /{ }^{34} \mathrm{~S}=24.7 \pm 3.5$ in CS, all compatible with terrestrial values. The ratio ${ }^{12} \mathrm{C} /{ }^{13} \mathrm{C}=109 \pm 14$ in $\mathrm{HCN}$ is marginally higher than terrestrial and ${ }^{14} \mathrm{~N} /{ }^{15} \mathrm{~N}=145 \pm 12$ in $\mathrm{HCN}$ is half the Earth ratio. Several upper limits for $\mathrm{D} / \mathrm{H}$ or ${ }^{12} \mathrm{C} /{ }^{13} \mathrm{C}$ in other molecules are reported. From our observation of HDO in comet C/2014 Q2 (Lovejoy), we report the first D/H ratio in an Oort Cloud comet that is not larger than the terrestrial value. On the other hand, the observation of the same HDO line in the other Oort-cloud comet, C/2012 F6 (Lemmon), suggests a $\mathrm{D} / \mathrm{H}$ value four times higher. Given the previous measurements of $\mathrm{D} / \mathrm{H}$ in cometary water, this illustrates that a diversity in the $\mathrm{D} / \mathrm{H}$ ratio and in the chemical composition, is present even within the same dynamical group of comets, suggesting that current dynamical groups contain comets formed at very different places or times in the early solar system.
\end{abstract}

Key words. radio lines: planetary systems - submillimeter: planetary systems - comets: individual: C/2012 F6 (Lemmon) comets: individual: C/2014 Q2 (Lovejoy) - comets: general

\section{Introduction}

Comets are the most pristine remnants of the formation of the solar system 4.6 billion years ago. Investigating the composition of cometary ices provides clues to the physical conditions and chemical processes at play in the primitive solar nebula. Comets

\footnotetext{
* Based on observations carried out with the IRAM $30 \mathrm{~m}$ telescope. IRAM is supported by INSU/CNRS (France), MPG (Germany) and IGN (Spain).

$\star \star$ Odin is a Swedish-led satellite project funded jointly by the Swedish National Space Board (SNSB), the Canadian Space Agency (CSA), the National Technology Agency of Finland (Tekes) and the Centre National d'Études Spatiales (CNES, France). The Swedish Space Corporation is the prime contractor, also responsible for Odin operations.

$\star \star \star$ The spectra dataset is only available at the CDS via anonymous ftp to cdsarc.u-strasbg. fr (130.79.128.5) or via

http://cdsarc.u-strasbg.fr/viz-bin/qcat?]/A+A/589/A78
}

may also have played a role in the delivery of water and organic material to the early Earth (see Hartogh et al. 2011, and references therein). The latest simulations of the early solar system evolution (Brasser \& Morbidelli 2013; O'Brien et al. 2014), suggest a more complex scenario. On the one hand, ice-rich bodies formed beyond Jupiter may have been implanted in the outer asteroid belt and participated in the supply of water to the Earth or, on the other hand, current comets coming from either the Oort Cloud or the scattered disk of the Kuiper belt may have formed in the same trans-Neptunian region sampling the same diversity of formation conditions. Understanding the diversity in composition and isotopic ratios of the comet material is thus essential in order to assess such scenarios (Altwegg \& Bockelée-Morvan 2003; Bockelée-Morvan et al. 2015).

The recent years have seen significant improvement in the sensitivity and spectral coverage of millimeter receivers. The EMIR receivers (Carter et al. 2012) at the Institut de radioastronomie millimétrique (IRAM) are equipped with a fast 
Fourier transform spectrometer that offers a wide frequency coverage at a high spectral resolution $(0.2 \mathrm{MHz})$. The combination enables sensitive spectral surveys of cometary atmospheres and simultaneous observations of several molecules, including isotopologues in brighter comets. We report here observations of isotopic ratios with the IRAM $30 \mathrm{~m}$ radio telescope in two very active (maximum water outgassing rate close to $10^{30}$ molec s $^{-1}$ ) Oort cloud comets, C/2012 F6 (Lemmon) and C/2014 Q2 (Lovejoy), carried out in 2013 and 2015. They are both dynamically old Oort cloud comets: an original orbital period of 9800 years and an orbit inclination of $83^{\circ}$ for comet Lemmon, and a period of 11000 years and an inclination of $80^{\circ}$ for comet Lovejoy.

The analysis of the observation in terms of molecular abundances and detection of rare and new molecular species has been reported (Biver et al. 2014, 2015). In the present article we concentrate on the measurement of several isotopic ratios. We report the detection of HDO in both comets. The compounds $\mathrm{H}_{2}^{16} \mathrm{O}$ and $\mathrm{H}_{2}^{18} \mathrm{O}$ were detected in comet Lovejoy with the Odin submillimeter space observatory, which helped to accurately determine the $\mathrm{D} / \mathrm{H}$ and ${ }^{16} \mathrm{O} /{ }^{18} \mathrm{O}$ ratio in water in this comet.

\section{Observations}

\subsection{IRAM Observations}

Comet C/2014 Q2 (Lovejoy) was observed with the IRAM $30 \mathrm{~m}$ radio telescope during two periods: on 13.8, 15.8, and 16.8 January 2015 (geocentric distance $\Delta=0.496-0.528$ AU) and on 23.7, 24.7, 25.7, and 26.7 January $2015(\Delta=$ $0.624-0.675 \mathrm{AU})$ under very good weather conditions. The heliocentric distances were 1.31 and 1.29 AU, respectively. Perihelion was on 30.07 January UT, at 1.290 AU from the Sun. The 13-25 and 26 January observations were conducted with the EMIR $1 \mathrm{~mm}$ and $3 \mathrm{~mm}$ receivers, respectively. The main backend used is a Fourier transform spectrometer, which covers a frequency range of $2 \times 8 \mathrm{GHz}$ (two sidebands separated by $8 \mathrm{GHz}$, each in two linear polarizations) in a single setup, with a high spectral resolution of $200 \mathrm{kHz}$. The spectral resolution (0.3-0.2 $\mathrm{km} \mathrm{s}^{-1}$ when converted into Doppler velocity) allows the velocity profiles of the narrow cometary lines $\left(\sim 2 \mathrm{~km} \mathrm{~s}^{-1}\right)$ to be resolved. We also used the high resolution VESPA autocorrelator set to $40 \mathrm{kHz}$ sampling on dedicated lines of interest (e.g., $\mathrm{CH}_{3} \mathrm{OH}\left(5_{+2}-4_{+1} E\right)$ and $\left.\mathrm{H}^{15} \mathrm{CN}(3-2)\right)$, but VESPA units can only cover lines within a $0.5 \mathrm{GHz}$ window centered at $6.25 \mathrm{GHz}$ in the IF band (upper and lower side band). Using four different tunings we covered the 210-218, 225-233, and 240-272 GHz frequency ranges and 85-93 and 101-109 GHz.

The half power beam width of the IRAM $30 \mathrm{~m}$ telescope in the $1 \mathrm{~mm}$ band ranges from $9.1^{\prime \prime}$ to $11.6^{\prime \prime}$, which corresponds to 3300 to $5400 \mathrm{~km}$ at the comet distance $\left(22-28^{\prime \prime}\right.$ at $3 \mathrm{~mm}$ corresponding to $11000-14000 \mathrm{~km}$ on $26.7 \mathrm{Jan}$.). Given the expansion velocity of the coma $\left(\sim 0.8 \mathrm{~km} \mathrm{~s}^{-1}\right)$ and heliocentric distance, this means that we are not very sensitive to the photodissociation rate of the molecules, provided that the molecule lifetime at $1 \mathrm{AU}$ is larger than $4000 \mathrm{~s}$. The pointing accuracy $\left(1^{\prime \prime}-2^{\prime \prime}\right)$ was regularly checked on reference pointing sources and also on the comet with coarse maps. The time variation of the activity of the comet could be monitored with the multiple strong $\mathrm{CH}_{3} \mathrm{OH}$ lines present in all setups. We did not see any variations significantly larger than $\pm 20 \%$ during the observations $\left(Q_{\mathrm{CH}_{3} \mathrm{OH}}=1.2 \pm 0.2 \times 10^{28}\right.$ molec s $^{-1}, 13-16$ January, and $1.4 \pm 0.2 \times 10^{28}$ molec s$^{-1}, 23-25$ January), which justified the averaging of several days of observations.
Comet C/2012 F6 (Lemmon) was observed in March and April 2013 (as already presented in Biver et al. 2014). Perihelion was on 24.51 March 2013 UT at 0.731 AU from the Sun. We mostly used the same tunings as for comet Lovejoy with the EMIR 1mm receiver combined with the FTS and VESPA spectrometers. The best weather conditions were found on 14.5 and 18.5 March, but with a comet at low elevation $\left(15-20^{\circ}\right)$, and on 6.5 April 2013. We covered the 240-272 GHz frequency range and obtained noisier data on the 85-93, 166-170, and 210-242 GHz bands with the EMIR $3 \mathrm{~mm}, 2 \mathrm{~mm}$, and $1 \mathrm{~mm}$ receivers, respectively. A summary of the observational setups is given in Table A.1.

In this paper we focus only on the measurement of isotopic ratios, and spectra of isotopologues are presented in Figs. 3-8. The chemical inventory of these comets based on these observations with the IRAM telescope has been presented in Biver et al. $(2014,2015)$ and will be further detailed in a future paper.

\subsection{Odin observations of comet C/2014 Q2 (Lovejoy)}

Because comet C/2014 Q2 (Lovejoy) clearly became a very active comet, observations with the Odin $1.1 \mathrm{~m}$ submillimeter satellite (Frisk et al. 2003) were triggered on a late notice. Observations took place between 30.5 January and 3.4 February 2015. These observations were scheduled to map the emission of $\mathrm{H}_{2}^{16} \mathrm{O}$ at $556.9 \mathrm{GHz}$, follow its temporal evolution, and detect the $\mathrm{H}_{2}^{18} \mathrm{O}$ line at $547.7 \mathrm{GHz}$. The half power beamwidth is close to $2.1^{\prime}$ at these frequencies and the main beam efficiency is 0.89 . Odin uses three spectrometers: a $1 \mathrm{GHz}$ bandwidth acousto-optical spectrometer (AOS with $0.6 \mathrm{MHz}$ sampling) and two autocorrelators (AC1 and AC2) used in their highest resolution mode ( $\sim .15 \mathrm{MHz}$ with $100 \mathrm{MHz}$ bandwidth). For the first setup, two receivers tuned to the $\mathrm{H}_{2}^{16} \mathrm{O}$ line were used in parallel, coupled to the three spectrometers: AOS and AC2 on receiver 555-B2 and $\mathrm{AC} 1$ on 549-A1. For the second setup, the AOS was connected to the 572-B1 receiver tuned near the ammonia line at $572.5 \mathrm{GHz}$, but not frequency locked, while AC2 was connected to the receiver 555-B2 and AC1 to 549-A1, both tuned to the $\mathrm{H}_{2}^{18} \mathrm{O}$ line.

As Odin is in a helio-synchronous polar Earth orbit at $550 \mathrm{~km}$ altitude, the comet was only observable during $~ 55 \mathrm{~min}$ of each 96 min orbit. The Earth was in the field of view during the remaining time, and the atmospheric lines were used to calibrate the frequency scale. Some of the observations failed to track the comet correctly, but half were successful and provided good results. Spectra of the nucleus-centered $\mathrm{H}_{2}^{16} \mathrm{O}$ and $\mathrm{H}_{2}^{18} \mathrm{O}$ lines are shown in Fig. 3 and a map of the $\mathrm{H}_{2}^{16} \mathrm{O}$ line is shown in Fig. 1.

\section{Modeling of the lines and model parameters}

\subsection{Velocity and outgassing pattern}

The mean gas expansion velocity was derived from the shape of the lines with the highest signal-to-noise ratio. We determined a value of 1.1 to $1.0 \mathrm{~km} \mathrm{~s}^{-1}$ for comet Lemmon and $0.8 \mathrm{~km} \mathrm{~s}^{-1}$ for comet Lovejoy (Table A.1). As discussed hereafter, comet Lovejoy was observed with the larger beam of Odin; a value of $0.85 \mathrm{~km} \mathrm{~s}^{-1}$ provided a better fit to the width of the water lines. This is expected, as acceleration of the gas expansion velocity in the coma is predicted and observed in the outer part of the comae of active comets. 


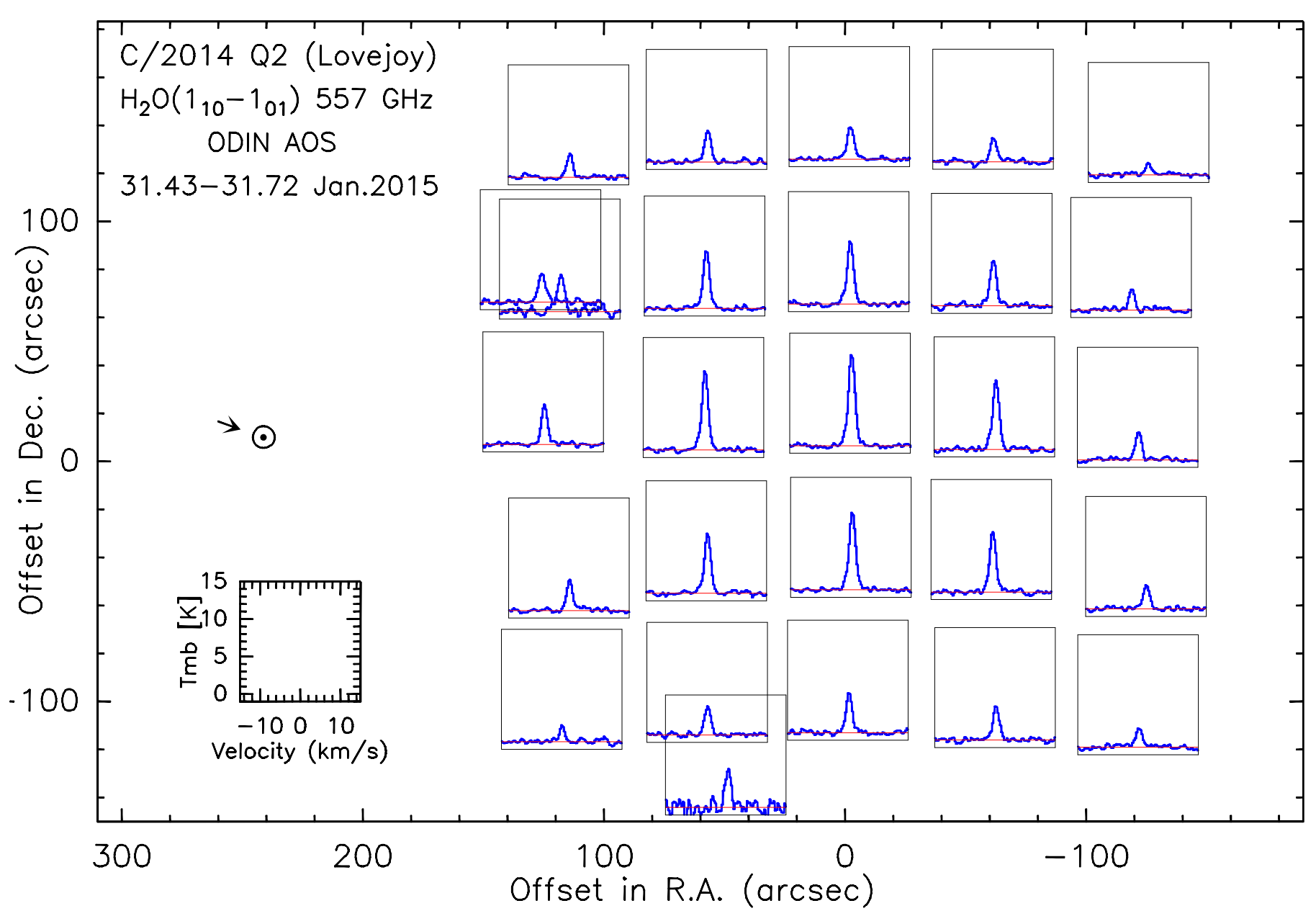

Fig. 1. Map of the $\mathrm{H}_{2}^{16} \mathrm{O}\left(1_{10}-1_{01}\right)$ line obtained with Odin and its acousto-optical spectrometer in comet Lovejoy. The arrow provides the projected direction of the Sun (phase angle was $50^{\circ}$ ), but the water emission does not exhibit any significant asymmetry.

\subsection{Temperature and collisional excitation}

For all molecules we used the latest spectroscopic data available in the JPL (Pickett et al. 1998) and CDMS (Müller et al. 2005) databases, both for line identification and computation of line strengths. We employed the code previously used for other comets (Biver et al. 2007; Hartogh et al. 2011; Bockelée-Morvan et al. 2012) to compute the excitation of the rotational levels of the molecules and the line intensities. We take into account the pumping of the rotational levels by the fluorescence of the infrared vibrational bands, which is not expected to play a major role at the cometocentric distances $\leq 5000 \mathrm{~km}$ sampled in the case of comet Lovejoy. In our model molecules slowly evolve from the local thermal equilibrium ( $T=100-110$ and $73 \mathrm{~K}$, for comets Lemmon and Lovejoy, respectively; Table A.1) maintained by collisions with neutrals and electrons close to the nucleus to spontaneous decay of the rotational population in the less dense parts of the coma (Biver et al. 2000, 2006). Within the accuracy of the detections, line intensity ratios (or rotational temperatures) for methanol, and also for most other species, are in agreement with the model (e.g., $T_{\text {rot }}\left(\mathrm{CH}_{3} \mathrm{CHO}\right.$, Lovejoy) $=67 \pm 15 \mathrm{~K}$ for $68 \mathrm{~K}$ predicted). The density is described with the Haser model, using lifetimes from Crovisier (1994), Bockelée-Morvan et al. (2000), and Crovisier et al. (2004a,b). Line intensities are computed with a radiative transfer code that takes opacity effects into account. Except for $\mathrm{H}_{2}^{16} \mathrm{O}$ and $\mathrm{HCN}$, lines are optically thin, meaning that line intensities are proportional to the production rates.

\section{Water production rate and time evolution}

\subsection{Odin maps and excitation of water in the coma of comet Lovejoy}

Several maps (e.g., Fig. 1) of the water emission were performed for comet Lovejoy with Odin in order to precisely derive the water production rate. The extension of the emission of optically thick submillimeter water lines in cometary comae is in large part governed by the excitation mechanism of the water rotational levels. It depends both on the temperature profile and collision rates with electrons and neutrals in the inner part of the coma (Biver et al. 2007; Hartogh et al. 2011; Bockelée-Morvan et al. 2012). However, in the outer part (beyond $150^{\prime \prime}$ ) the line intensity mostly depends on the water production rate (and assumed photo-dissociation lifetime), and very little on the assumed temperature profile. Dividing the gas temperature by a factor of 2 only increases the derived production rate by $10 \%$. We used the same excitation parameters for the $\mathrm{H}_{2}^{16} \mathrm{O}$ observations with Odin, as those derived for the molecular lines observed with the IRAM $30 \mathrm{~m}$ instrument: a constant temperature of $73 \mathrm{~K}$ throughout the coma and an electron density scaling factor $x_{\text {ne }}=0.5$ (Zakharov et al. 2007; Biver et al. 2007). The expansion velocity inferred from the $\mathrm{H}_{2}^{16} \mathrm{O}$ and $\mathrm{H}_{2}^{18} \mathrm{O}$ line widths is $v_{\exp }=0.85 \mathrm{~km} \mathrm{~s}^{-1}$, slightly 
Table 1. Periodic variation of water production in comet Lovejoy.

\begin{tabular}{|c|c|c|c|c|c|c|}
\hline \multicolumn{7}{|c|}{ Odin measurements 29 January-3 February $2015, r_{\mathrm{h}}=1.29 \mathrm{AU}$} \\
\hline \multirow[t]{3}{*}{ Data points } & \multirow[t]{3}{*}{ Molecule } & \multicolumn{4}{|c|}{ Production rate variation fitted ${ }^{a}$} & \multirow[t]{3}{*}{$\chi_{v}^{2}$} \\
\hline & & $Q_{0}$ & $\Delta Q$ & $T_{\mathrm{p}}$ & $T_{0}$ & \\
\hline & & \multicolumn{2}{|c|}{$\left[10^{27}\right.$ molec s $\left.^{-1}\right]$} & [days] & [UT day] & \\
\hline $23^{b}$ & $\mathrm{H}_{2}^{16} \mathrm{O}$ & $751.6 \pm 29.5$ & $140 \pm 21$ & $0.938 \pm 0.014$ & $31.797 \pm 0.038-J a n$ & 1.03 \\
\hline $23^{b}$ & $\mathrm{H}_{2}^{16} \mathrm{O}$ & $724.4 \pm 14.6$ & $141 \pm 22$ & $0.935^{d}$ & 31.742-Jan. ${ }^{d}$ & 1.09 \\
\hline $23^{b}$ & $\mathrm{H}_{2}^{16} \mathrm{O}$ & $774.0 \pm 12.4$ & $0.0^{c}$ & - & - & 2.78 \\
\hline 15 & $\mathrm{H}_{2}^{18} \mathrm{O}$ & $1.524 \pm 0.065$ & $0.374 \pm 0.085$ & $0.922 \pm 0.031$ & $31.400 \pm 0.035-J a n$ & 1.21 \\
\hline $15^{b}$ & $\mathrm{H}_{2}^{18} \mathrm{O}$ & $1.453 \pm 0.062$ & $0.314 \pm 0.083$ & $0.935^{d}$ & 31.742-Jan. ${ }^{d}$ & 1.23 \\
\hline 15 & $\mathrm{H}_{2}^{18} \mathrm{O}$ & $1.421 \pm 0.055$ & $0.0^{c}$ & - & - & 2.44 \\
\hline $38^{b}$ & $\mathrm{H}_{2}^{16} \mathrm{O}, \mathrm{H}_{2}^{18} \mathrm{O}^{e}$ & $724 \pm 17$ & $147 \pm 19$ & $0.939 \pm 0.013$ & $31.912 \pm 0.022-J a n$ & 1.00 \\
\hline
\end{tabular}

Notes. ${ }^{(a)} Q=Q_{0}+\Delta Q \times \sin \left(2 \pi\left(t-T_{0}\right) / T_{\mathrm{p}}\right)$, where $T_{\mathrm{p}}$ is the period in days of the fitted sine variation and $T_{0}$ the reference time for the phase. ${ }^{(b)}$ Including $5 \%$ uncertainty due to a $10^{\prime \prime}$ pointing uncertainty. ${ }^{(c)}$ Fit of constant production. ${ }^{(d)}$ fixed value (see text). ${ }^{(e)}$ Assuming $\mathrm{H}_{2}^{16} \mathrm{O} / \mathrm{H}_{2}^{18} \mathrm{O}=500$.

larger than for the lines observed with the smaller beam of the IRAM $30 \mathrm{~m}$ telescope. The fit to the radial profile of the line intensity from the map (Fig. 1) is satisfactory and corresponds to $Q_{\mathrm{H}_{2} \mathrm{O}}=8.7 \pm 0.7 \times 10^{29}$ molec s${ }^{-1}$ and the reduced $\chi_{v}^{2}=2.4$ when we include the $5 \%$ uncertainty due to the $10^{\prime \prime}$ (Frisk et al. 2003) pointing uncertainty. Taking into account an increase in the velocity with distance from the nucleus does not significantly change the goodness of the fit and the derived production rate.

\subsection{Periodic variation in $\mathrm{H}_{2}^{16} \mathrm{O}$ and $\mathrm{H}_{2}^{18} \mathrm{O}$ production rates}

Since $\mathrm{H}_{2}^{16} \mathrm{O}$ and $\mathrm{H}_{2}^{18} \mathrm{O}$ measurements with Odin were not simultaneous, but interlaced, in order to derive an accurate $\mathrm{H}_{2}^{16} \mathrm{O} / \mathrm{H}_{2}^{18} \mathrm{O}$ production rate ratio it is necessary to determine if significant short-time variation of the activity is present. Inspection of production rates does suggest that time variation is present in the data. Since the observations of $\mathrm{H}_{2}^{18} \mathrm{O}$ constituted a series of ten successive Odin orbits, we did a time averaging of $\approx 2.5 \mathrm{~h}$, corresponding to two consecutive orbits of observations, yielding a sufficient signal-to-noise ratio $(5-10)$ to look for time variations. We fitted a sinusoidal time variation to the individual measurements of the production rates of $\mathrm{H}_{2}^{16} \mathrm{O}$ and $\mathrm{H}_{2}^{18} \mathrm{O}$, independently. We only selected the $\mathrm{H}_{2}^{16} \mathrm{O}$ measurements with pointing offsets less than $\sim 100^{\prime \prime}$. The results are provided in Table 1. For both molecules, the sinusoidal fit is better than assuming no time variation $\left(\chi_{v}^{2}\right.$ reduced by a factor $\left.\sim 2.5\right)$, and the inferred period is similar $\left(T_{\mathrm{p}}=0.922-0.940\right.$ day $)$. A simulation of periodic variations of the production rates anticipated a longer delay between peak outgassing and peak signal for $\mathrm{H}_{2}^{16} \mathrm{O}$ than $\mathrm{H}_{2}^{18} \mathrm{O}$ ( 0.25 versus 0.14 day), which we took into account. We found different reference times $T_{0}$ for $\mathrm{H}_{2}^{16} \mathrm{O}$ and $\mathrm{H}_{2}^{18} \mathrm{O}$, but these are strongly correlated to the $T_{\mathrm{p}}$ value. Formally, the $T_{\mathrm{p}}$-independent $1 \sigma$ uncertainty $\delta T_{0}$ is on the order of 0.4 days. We also tried to fit the data with the same time dependence for $\mathrm{H}_{2}^{16} \mathrm{O}$ and $\mathrm{H}_{2}^{18} \mathrm{O}$, using a fixed mean period of $T_{\mathrm{p}}=0.935$ days (weighted average) and a corresponding reference time 31.742 Jan. $2015 \mathrm{UT}$. The goodness of the fits is similar (Table 1). A larger damping of the apparent production rate amplitude was expected for $\mathrm{H}_{2}^{16} \mathrm{O}$ due to optical depth effects. From the observations the effect is not so obvious: $\triangle Q / Q_{0}$ is only slightly smaller for $\mathrm{H}_{2}^{16} \mathrm{O}$ than for $\mathrm{H}_{2}^{18} \mathrm{O}(0.19$ versus 0.24). We did not investigate the possible variation of the gas temperature with the production rate, but this could explain a

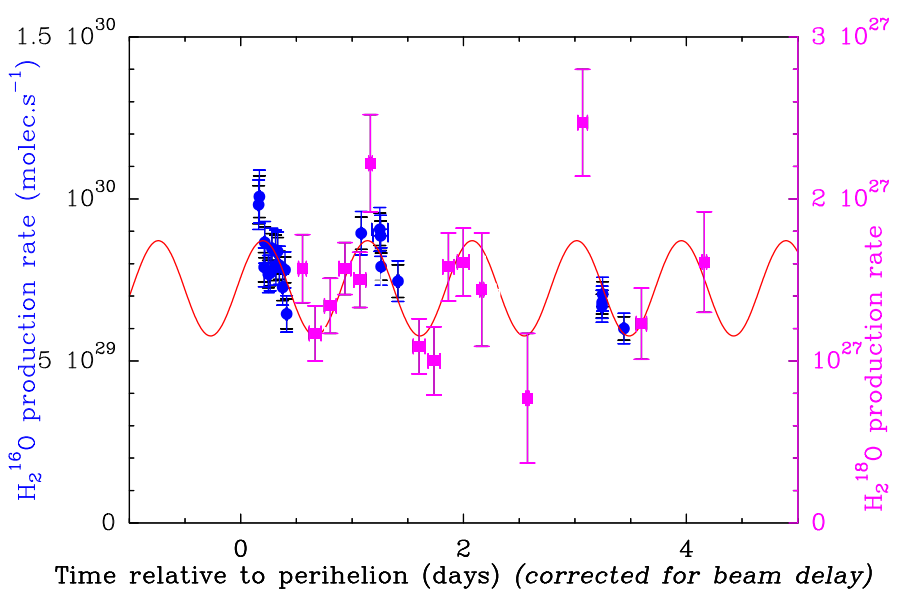

Fig. 2. $\mathrm{H}_{2}^{16} \mathrm{O}$ (left vertical scale) and $\mathrm{H}_{2}^{18} \mathrm{O}$ (pink, right vertical scale) production rates in comet Lovejoy from Odin observations. Horizontal scale is the time relative to perihelion (30.069 January 2015 UT) in days, minus the expected delay between peak outgassing and peak intensity due to beam dilution and opacity effect for a periodic outgassing with similar periodicity. Production rates are apparent production rates computed in the stationary regime assumption. For $\mathrm{H}_{2}^{16} \mathrm{O}$ the larger error bar includes a $5 \%$ uncertainty due to the $10^{\prime \prime}$ pointing uncertainty. $\mathrm{H}_{2}^{18} \mathrm{O}$ uncertainty is dominated by statistical noise. The least square fit to the combined production rate (last line of Table 1) is overplotted.

variation of the line intensity with time that was larger than anticipated.

We then combined both $Q_{\mathrm{H}_{2}^{16} \mathrm{O}}$ and $Q_{\mathrm{H}_{2}^{18} \mathrm{O}}$ to derive our best estimate of the water production rate as a function of time during the period 30 January to 3 February 2015 (last line of Table 1). Figure 2 shows the time evolution of the production rates measured for the two water isotopologues and best fit.

\subsection{Reference water production rates}

The reference water production rates were primarily derived from contemporaneous observations of the $\mathrm{OH}$ radical maser lines at $18 \mathrm{~cm}$ with the Nançay radio telescope. During the 12.8-16.8 January 2015 observing period of comet Lovejoy, both observations centered on the comet and at 3.0' offset position were used to better constrain the quenching of the 
Table 2. Isotopic ratios in comet C/2014 Q2 and C/2012 F6.

\begin{tabular}{ccc}
\hline \hline Isotopic ratio & Molecule & Value \\
\hline \multicolumn{2}{c}{ Comet C/2012 $\mathrm{F6}$ (Lemmon) } & Mar.-Apr. 2013 \\
\hline $\mathrm{D} / \mathrm{H}$ & $\mathrm{H}_{2} \mathrm{O}$ & $6.5 \pm 1.6 \times 10^{-4}$ \\
& $\mathrm{HCN}$ & $<0.045$ \\
${ }^{12} \mathrm{C} /{ }^{13} \mathrm{C}$ & $\mathrm{HCN}$ & $124 \pm 64$ or $\geq 89^{b}$ \\
${ }^{14} \mathrm{~N} /{ }^{15} \mathrm{~N}$ & $\mathrm{HCN}$ & $152 \pm 72$ or $\geq 106^{b}$ \\
${ }^{32} \mathrm{~S} /{ }^{34} \mathrm{~S}$ & $\mathrm{CS}$ & $20 \pm 5$ \\
& $\mathrm{H}_{2} \mathrm{~S}$ & $>3.5$ \\
\hline $\mathrm{Comet} \mathrm{C} / 2014 \mathrm{Q}^{2}$ (Lovejoy) Jan. 2015 \\
\hline $\mathrm{D} / \mathrm{H}$ & $\mathrm{H}_{2} \mathrm{O}$ & $1.4 \pm 0.4 \times 10^{-4}$ \\
& $\mathrm{HCN}$ & $<0.006$ \\
& $\mathrm{H}_{2} \mathrm{~S}$ & $<0.017$ \\
$\mathrm{H}_{2} \mathrm{CO}$ & $<0.007$ \\
${ }^{12} \mathrm{C} /{ }^{13} \mathrm{C}$ & $\mathrm{HCN}^{\mathrm{CH}_{3} \mathrm{OH}}$ & $109 \pm 14$ \\
${ }^{14} \mathrm{~N} /{ }^{15} \mathrm{~N}$ & $\mathrm{HCN}_{61}$ & $145 \pm 12$ \\
${ }^{16} \mathrm{O} /{ }^{18} \mathrm{O}$ & $\mathrm{H}_{2} \mathrm{O}$ & $499 \pm 24^{a}$ \\
${ }^{32} \mathrm{~S} /{ }^{34} \mathrm{~S}$ & $\mathrm{CS}$ & $24.7 \pm 3.5$ \\
& $\mathrm{H}_{2} \mathrm{~S}$ & $>7$ \\
${ }^{32} \mathrm{~S} /{ }^{33} \mathrm{~S}$ & $\mathrm{CS}$ & $>50$ \\
\hline
\end{tabular}

Notes. ${ }^{(a)}$ From time variable fits of the production rates. ${ }^{(b)}$ Based only on the backends with the lowest noise.

maser inversion (Gerard et al. 1998) yielding an average water production rate $Q_{\mathrm{H}_{2} \mathrm{O}}=5.0 \pm 0.2 \times 10^{29}$ molec s$^{-1}$ (Biver et al. 2015). For other periods and for comet Lemmon, the observations of the $\mathrm{OH}$ radical could not be used to derive an accurate water production rate owing to significant uncertainties in the quenching of the maser inversion. We either used the water production rates reported elsewhere (Combi et al. 2014; Paganini et al. 2014) or made an interpolation from the Odin observations of comet Lovejoy at perihelion. Based on Nançay and Odin observations, we adopt a mean $Q_{\mathrm{H}_{2} \mathrm{O}}=5,5.5,6$, and $7 \times 10^{29}$ molec s $^{-1}$ for the 13-16 January, 13-25 January, 23-25 January, and 26 January-3 February 2015 time intervals, respectively, with a $\pm 20 \%$ time variation possible within each time interval. Observations done on a short time interval might be affected by a periodic time variation, but this was tracked from the monitoring of the methanol production lines, which are present in all IRAM observations settings (Table A.1).

\section{Isotopic ratios}

Table A.2 provides the list of molecular lines (main species and isotopologues) observed at IRAM in comets C/2012 F6 (Lemmon) in 2013 and in C/2014 Q2 (Lovejoy) in 2015 and considered in this study. Line intensities and production rates (or upper limits) derived using the models presented in Sect. 3 are given. The corresponding isotopic ratios or $3 \sigma$ limits are presented in Table 2.

\section{1. ${ }^{16} \mathrm{O} /{ }^{18} \mathrm{O}$ ratio in comet Lovejoy}

The analysis of Odin observations in Sect. 4.2 (Table 1) enabled us to derive an accurate $\mathrm{H}_{2}^{16} \mathrm{O} / \mathrm{H}_{2}^{18} \mathrm{O}$ production rate ratio. From the sinusoidal fits and derived mean $Q_{0}$ production rates, we obtain:

- $Q_{0}\left(\mathrm{H}_{2}^{16} \mathrm{O}\right) / Q_{0}\left(\mathrm{H}_{2}^{18} \mathrm{O}\right)=493 \pm 29$ for the independent fits;

- $Q_{0}\left(\mathrm{H}_{2}^{16} \mathrm{O}\right) / Q_{0}\left(\mathrm{H}_{2}^{18} \mathrm{O}\right)=499 \pm 24$ for the phased fits.

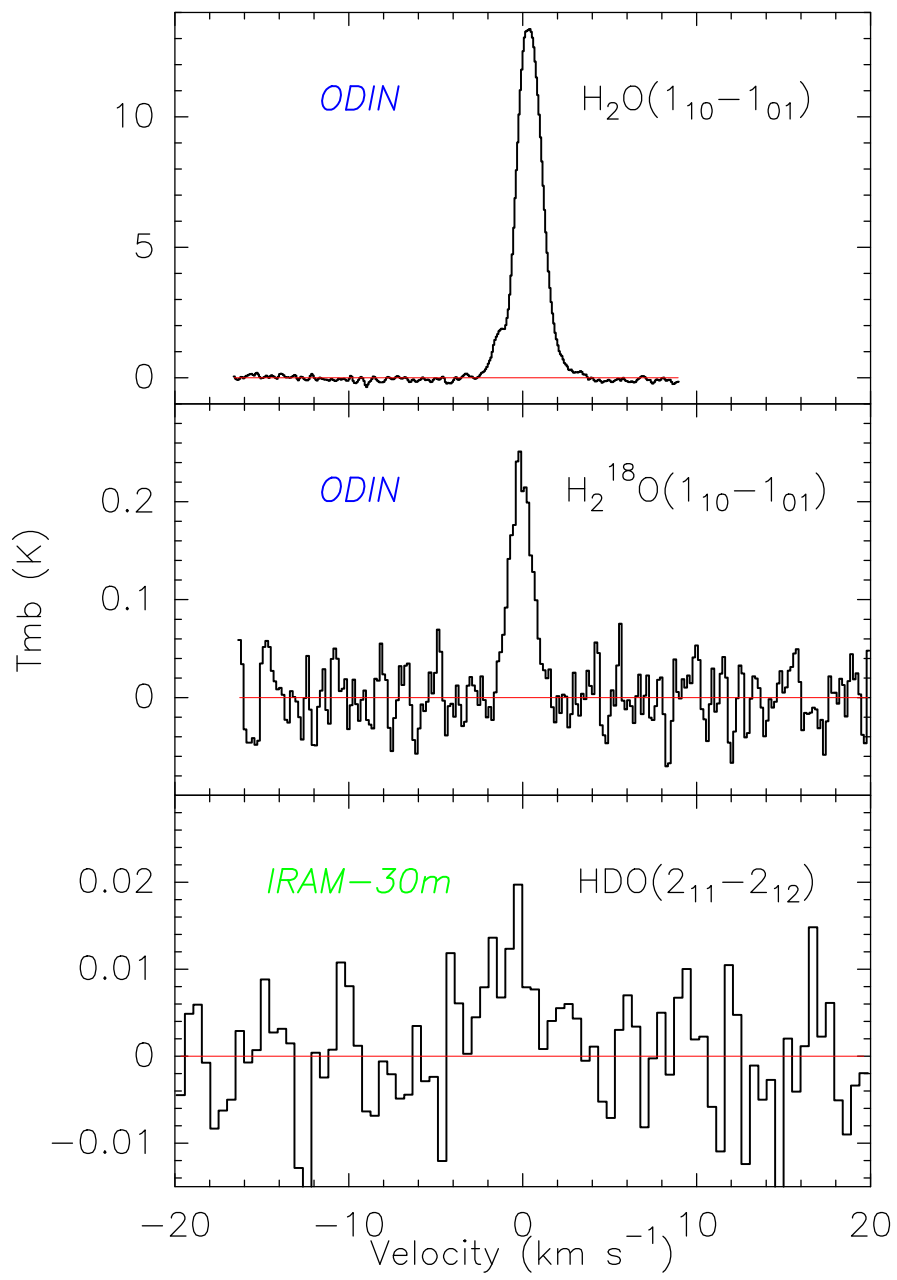

Fig. 3. Comet $\mathrm{C} / 2014$ Q2 (Lovejoy): average on-nucleus spectra of the $\mathrm{H}_{2}^{16} \mathrm{O} \quad\left(1_{10}-1_{01}\right)$ line at $556.936 \mathrm{GHz}$, and $\mathrm{H}_{2}^{18} \mathrm{O} \quad\left(1_{10}-1_{01}\right)$ line at $547.676 \mathrm{GHz}$ obtained with Odin between 30 January and 3 February 2015 . The spectrum of the HDO $\left(2_{11}-2_{12}\right)$ line at $241.561 \mathrm{GHz}$ observed with the IRAM $30 \mathrm{~m}$ telescope on 13-24 January 2015 is shown below. While the $\mathrm{H}_{2}^{18} \mathrm{O}$ and $\mathrm{HDO}$ lines are marginally blueshifted $\left(\Delta v=-0.07 \mathrm{~km} \mathrm{~s}^{-1}\right.$ in both cases) the $\mathrm{H}_{2}^{16} \mathrm{O}\left(1_{10}-1_{01}\right)$ line is asymmetric and red-shifted $\left(\Delta v=+0.33 \mathrm{~km} \mathrm{~s}^{-1}\right)$ due to self absorption by the cool gas in the foreground of this optically thick line. Vertical scale is main beam brightness temperature and horizontal scale Doppler velocity in the comet rest frame.

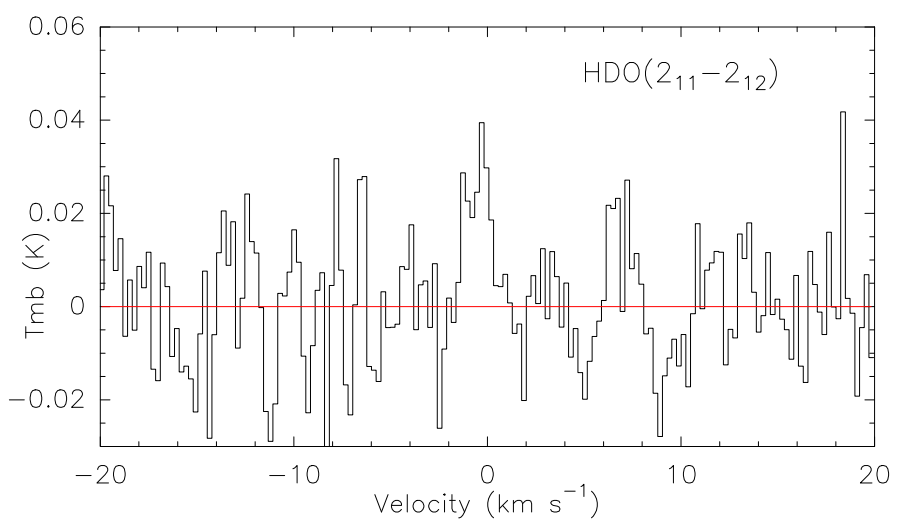

Fig. 4. Comet C/2012 F6 (Lemmon): average on-nucleus spectrum of the HDO $\left(2_{11}-2_{12}\right)$ line at $241.561 \mathrm{GHz}$ observed with the IRAM $30 \mathrm{~m}$ telescope between 14 March and 8 April 2013. Vertical scale is main beam brightness temperature and horizontal scale Doppler velocity in the comet rest frame. 


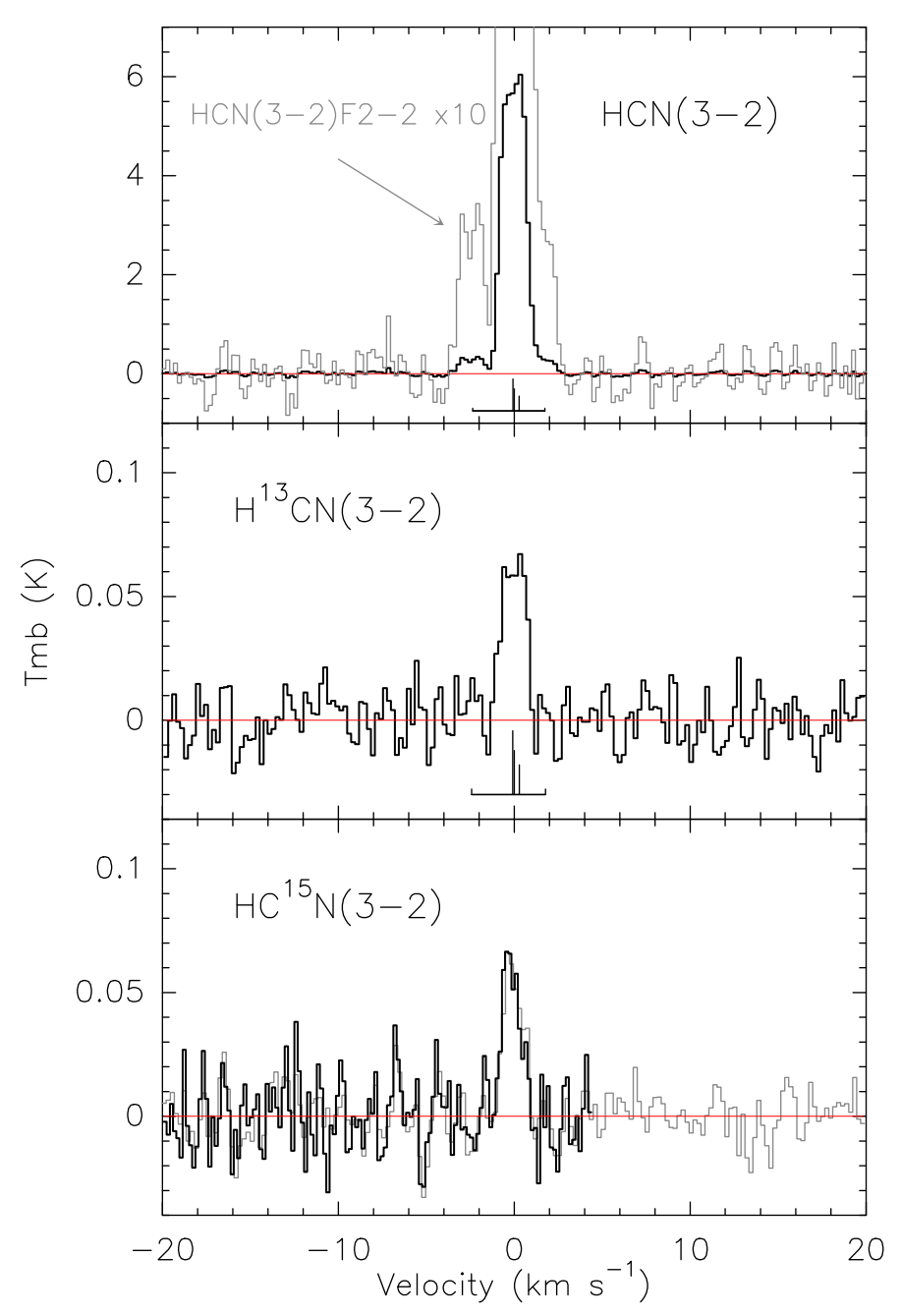

Fig. 5. Comet C/2014 Q2 (Lovejoy): average on-nucleus spectra of the $\mathrm{HCN}(3-2)$ line at $265.886 \mathrm{GHz}, \mathrm{H}^{13} \mathrm{CN}$ (3-2) line at $259.012 \mathrm{GHz}$, and $\mathrm{HC}^{15} \mathrm{~N}(3-2)$ line at $258.157 \mathrm{GHz}$ obtained with the IRAM $30 \mathrm{~m}$ telescope on 13-24 January 2015. For $\mathrm{HC}^{15} \mathrm{~N}(3-2)$ the spectrum obtained with the VESPA autocorrelator (thick line) is superimposed on the FTS spectrum. Vertical scale is main beam brightness temperature and horizontal scale Doppler velocity in the comet rest frame.

The second approach, which corresponds to a $\mathrm{H}_{2}^{16} \mathrm{O} / \mathrm{H}_{2}^{18} \mathrm{O}$ ratio that does not vary with time, yields ${ }^{16} \mathrm{O} /{ }^{18} \mathrm{O}=499 \pm 24$, which is exactly the terrestrial value (498.7).

\section{2. $D / H$ ratio}

Thanks to the wide frequency coverage of IRAM observations, lines of deuterated species of known cometary molecules were observed. None were detected except the HDO $\left(2_{11}-2_{12}\right)$ line at $241.562 \mathrm{GHz}$ (Fig. 3). This is not surprising as water is over a hundred times more abundant than $\mathrm{HCN}, \mathrm{H}_{2} \mathrm{~S}$, or $\mathrm{H}_{2} \mathrm{CO}$. Nevertheless, the upper limits on the $\mathrm{D} / \mathrm{H}$ ratio in $\mathrm{H}_{2} \mathrm{~S}$ or $\mathrm{H}_{2} \mathrm{CO}$ in comet Lovejoy are the lowest obtained so far in a comet.

\subsection{1. $\mathrm{D} / \mathrm{H}$ ratio in water in comet $\mathrm{C} / 2012 \mathrm{~F} 6$ (Lemmon)}

We observed the HDO $\left(2_{11}-2_{12}\right)$ line at $241.561 \mathrm{GHz}$ in comet C/2012 F6 (Lemmon) in March-April 2013. The detection of HDO (Fig. 4) is also marginal $(4 \sigma)$ and the retrieved intensity was possibly affected by poorer baselines on 8 April when we could not use the telescope wobbler to cancel sky emission. The

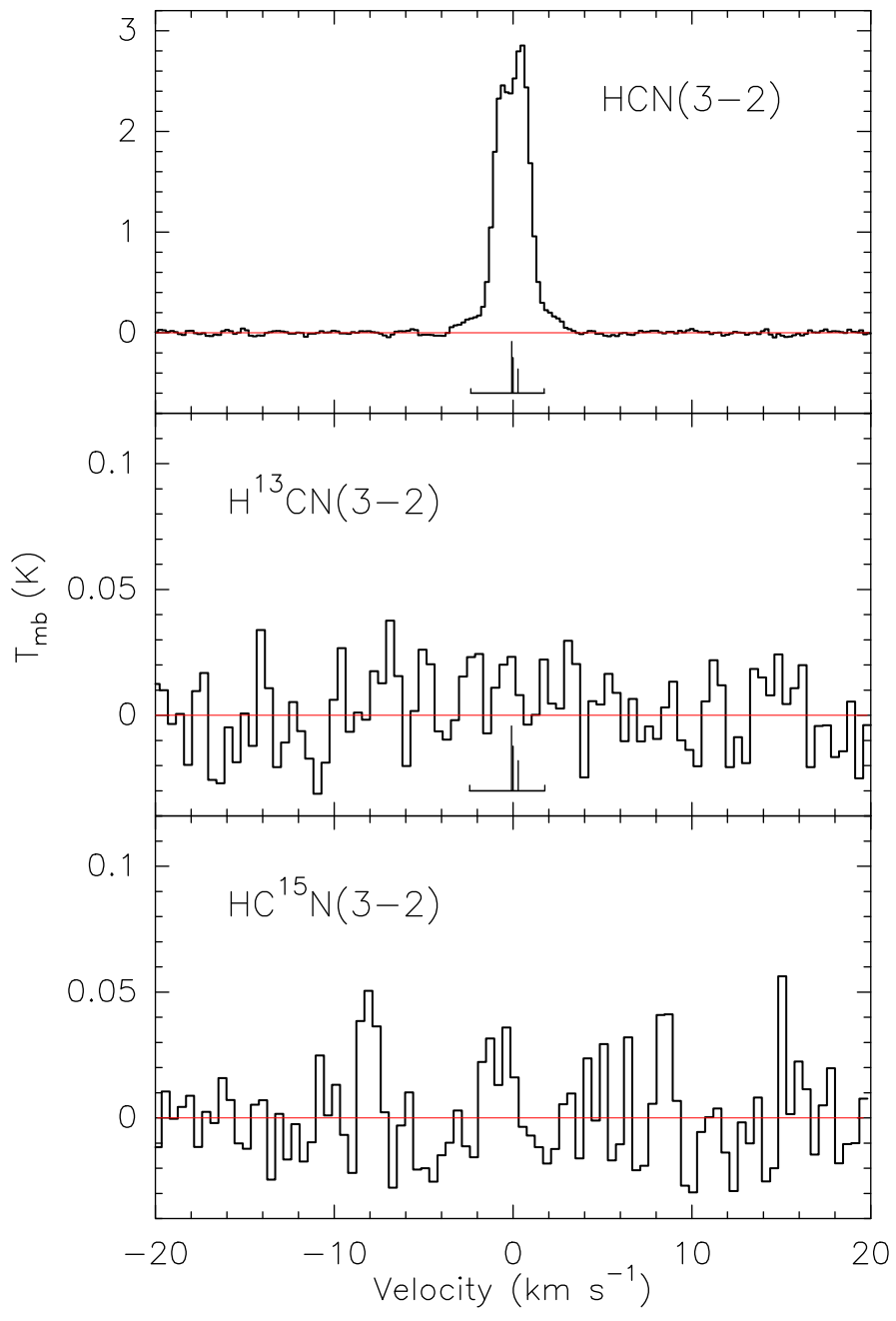

Fig. 6. Comet C/2012 F6 (Lemmon): average on-nucleus spectrum of the HCN (3-2) line at $265.886 \mathrm{GHz}$ obtained with the IRAM $30 \mathrm{~m}$ telescope between 14 March and 8 April 2013. Spectra covering the same velocity range obtained at similar times for $\mathrm{H}^{13} \mathrm{CN}(3-2)$ $(259.012 \mathrm{GHz})$ and $\mathrm{HC}^{15} \mathrm{~N}(3-2)(258.157 \mathrm{GHz})$ are also shown for comparison, but do not show a clear detection. Vertical scale is main beam brightness temperature and horizontal scale Doppler velocity in the comet rest frame.

inferred average HDO production rate for the period 14 March to 8 April 2013 is $Q_{\mathrm{HDO}}=13 \pm 3 \times 10^{26}$ molec s$^{-1}$, yielding $D / H=$ $6.5 \pm 1.6 \times 10^{-4}$. This is four times the Earth value (VSMOW $\left.D / H=1.56 \times 10^{-4}\right)$, the highest value found in a comet, but compatible with the Earth value at the $3 \sigma$ level.

\subsection{2. $\mathrm{D} / \mathrm{H}$ ratio in comet $\mathrm{C} / 2014 \mathrm{Q} 2$ (Lovejoy)}

The tracking of the comet activity via monitoring of the $\mathrm{CH}_{3} \mathrm{OH}$ production rate and the precise determination of the water outgassing rate using $\mathrm{OH}, \mathrm{H}_{2}^{16} \mathrm{O}$ and $\mathrm{H}_{2}^{18} \mathrm{O}$ make us confident that we have a good $\mathrm{H}_{2} \mathrm{O}$ production rate reference in order to derive the $\mathrm{D} / \mathrm{H}$ ratio. We report here the detection of $\mathrm{HDO}$ with the IRAM $30 \mathrm{~m}$ telescope in this comet. The HDO $\left(2_{11}-2_{12}\right)$ line was observed on 13, 15, 16, 23, and 24 January 2015. The average yields a $4 \sigma$ detection (Fig. 3) corresponding to $Q_{\mathrm{HDO}}=15.3 \pm 4.1 \times 10^{25} \mathrm{molec} \mathrm{s}^{-1}$, hence a $\mathrm{D} / \mathrm{H}$ ratio of $1.4 \pm 0.4 \times 10^{-4}$. Although the detection is marginal, in the worse case taking a $5 \sigma$ upper limit would yield $D / H<1.86 \times 10^{-4}$, suggesting that comet Lovejoy has a $\mathrm{D} / \mathrm{H}$ ratio for water similar 


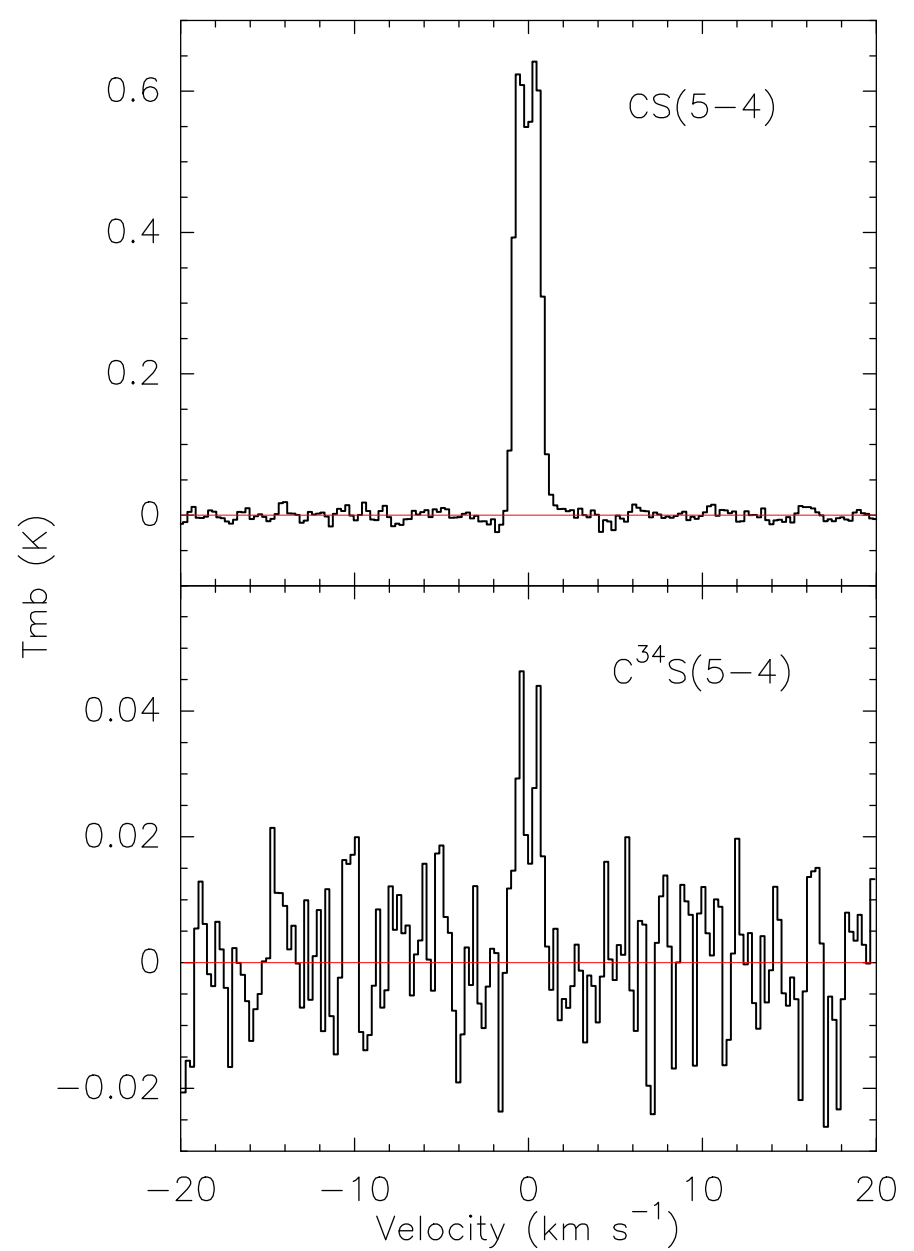

Fig. 7. Comet C/2014 Q2 (Lovejoy): average on-nucleus spectra of the $\mathrm{CS}$ (5-4) line at $244.936 \mathrm{GHz}$ and $\mathrm{C}^{34} \mathrm{~S}(5-4)$ line at $241.016 \mathrm{GHz}$ obtained with the IRAM $30 \mathrm{~m}$ telescope on 13-24 January 2015. Vertical scale is main beam brightness temperature and horizontal scale Doppler velocity in the comet rest frame.

to that of the Earth (VSMOW $D / H=1.56 \times 10^{-4}$ ), or possibly even lower. Previous measurements of the $\mathrm{D} / \mathrm{H}$ ratio in Oort cloud comets yielded values larger than VSMOW (see Sect. 6.1).

\section{3. ${ }^{14} \mathrm{~N} /{ }^{15} \mathrm{~N}$ ratio in $\mathrm{HCN}$}

One of the primary goals of the observing program of comet Lovejoy was to measure the ${ }^{14} \mathrm{~N} /{ }^{15} \mathrm{~N}$ ratio in $\mathrm{HCN}$. On January 13,15 , and 16 we first observed the main isotopologue transition HCN (3-2) at $265.886 \mathrm{GHz}$, then carried out longer integrations using the setup covering the $\mathrm{H}^{13} \mathrm{CN}(3-2)$ line at 259.012 $\mathrm{GHz}$ and the $\mathrm{HC}^{15} \mathrm{~N}(3-2)$ line at $258.157 \mathrm{GHz}$ (Fig. 5).

The HCN reference production rate was computed taking opacity effects into account. The average value for the 13-16 January period is $Q_{\mathrm{HCN}}=4.87 \pm 0.02 \times 10 \times$ $10^{26}$ molec s $^{-1}$, using pointing at the nucleus and at $5-8^{\prime \prime}$ offsets - which both yield exactly the same value. The HCN production rate based on the hyperfine component $\mathrm{HCN}(J=3-2, F=$ $2-2$ ) with a total statistical weight of $3.7 \%$ is marginally higher $(+14 \%, 2 \sigma)$, possibly because of contamination by the wings of the main HCN hyperfine components.

In order to minimize biases due to time variation of the outgassing and other observing uncertainties (calibration, pointing uncertainty, etc.), we rescaled the $\mathrm{HCN}$ production rate to the time when $\mathrm{H}^{13} \mathrm{CN}(3-2)$ and $\mathrm{HC}^{15} \mathrm{~N}(3-2)$ were observed, using

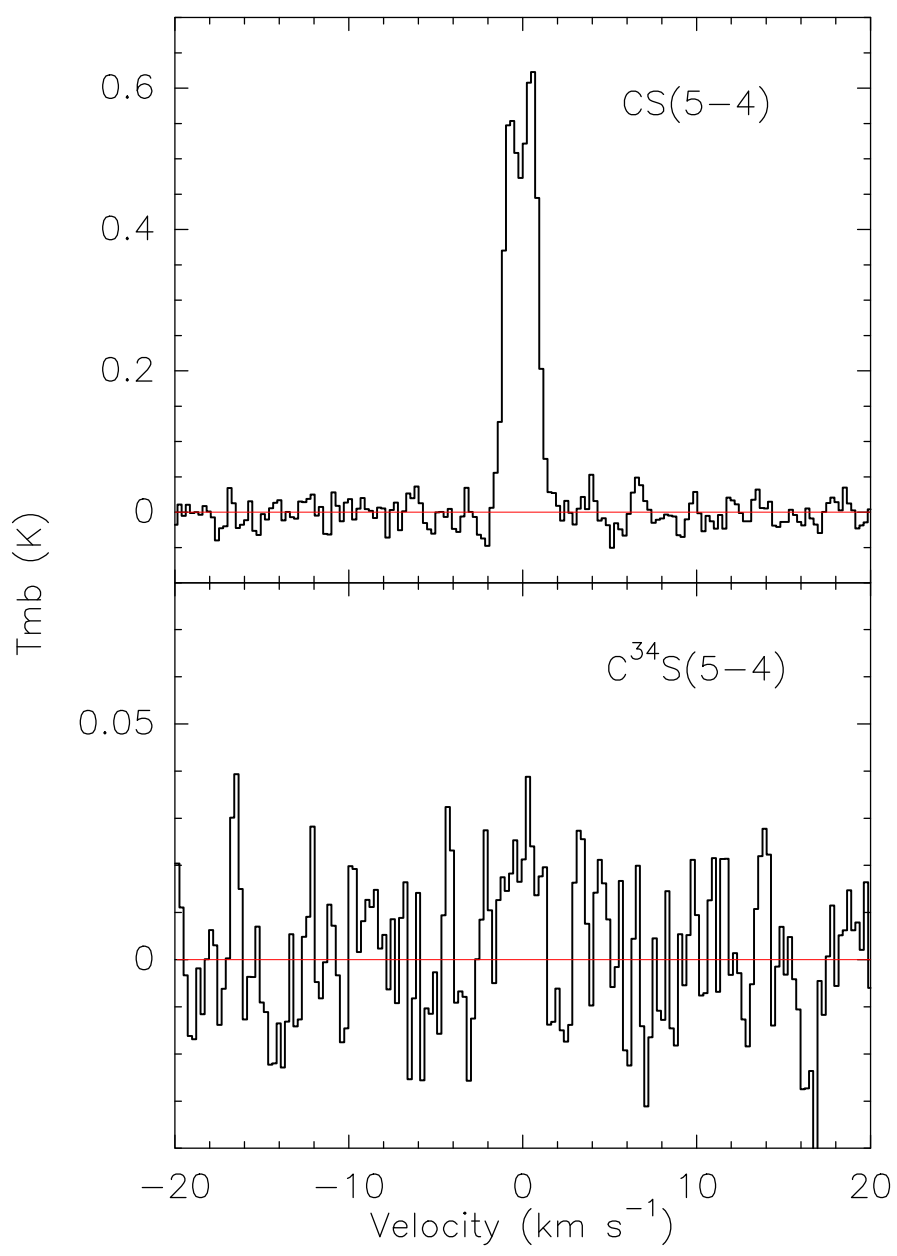

Fig. 8. Comet C/2012 F6 (Lemmon): average on-nucleus spectra of the $\mathrm{CS}(5-4)$ line at $244.936 \mathrm{GHz}$ and $\mathrm{C}^{34} \mathrm{~S}(5-4)$ line at $241.016 \mathrm{GHz}$ obtained with the IRAM 30 m telescope between 14 March and 8 April 2013. Vertical scale is main beam brightness temperature and horizontal scale Doppler velocity in the comet rest frame.

the $\mathrm{CH}_{3} \mathrm{OH}$ production rate as a reference since several methanol lines were observed in each setup. The correction applied to $Q_{\mathrm{HCN}}$ is $+10 \%$ for the $13-16$ January observations and $+27 \%$ for 23-25 January. The compound $\mathrm{HC}^{15} \mathrm{~N}(3-2)$ is clearly detected during both periods (signal-to-noise ratios of 9 and 6). The derived ${ }^{14} \mathrm{~N} /{ }^{15} \mathrm{~N}$ ratios are $145 \pm 16$ and $144 \pm 23$, for $13-16$ January and 23-25 January, respectively.

The compounds $\mathrm{HC}^{15} \mathrm{~N}(3-2)$ and $\mathrm{H}^{13} \mathrm{CN}(3-2)$ were not clearly detected (Fig. 6) in comet C/2012 F6 (Lemmon), but the $2 \sigma$ value or lower limit we obtained for the ${ }^{14} \mathrm{~N} /{ }^{15} \mathrm{~N}$ ratio in $\mathrm{HCN}$ $(\geq 106$ or $152 \pm 72$ ) is fully compatible with values found in other comets.

\section{4. ${ }^{12} \mathrm{C} /{ }^{13} \mathrm{C}$ ratio}

The $\mathrm{H}^{13} \mathrm{CN}$ (3-2) line at $259.012 \mathrm{GHz}$ is in the same spectral band as $\mathrm{HC}^{15} \mathrm{~N}(3-2)$. The production rates (assuming the same photo-dissociation lifetime as for $\mathrm{HCN}$ ) and relative abundances are derived in the same way for both molecules. Owing to its hyperfine structure similar to that of $\mathrm{H}^{12} \mathrm{CN}(3-2)$ (Fig. 5), the $\mathrm{H}^{13} \mathrm{CN}(3-2)$ line only contains $93 \%$ of the flux in the $\left(-1.2-1.2 \mathrm{~km} \mathrm{~s}^{-1}\right)$ window and this was taken into account.

The derived ${ }^{12} \mathrm{C} /{ }^{13} \mathrm{C}$ ratios in comet Lovejoy and Lemmon are $109 \pm 14$ and $124 \pm 64$, respectively. Within the uncertainties, 
they are compatible with the terrestrial value (89.7) although slightly higher ( $1.4 \sigma$ for Lovejoy). This trend was also observed for comet 17P/Holmes (Bockelée-Morvan et al. 2008) and Hale-Bopp (Jewitt et al. 1997). Combining the three ${ }^{12} \mathrm{C} /{ }^{13} \mathrm{C}$ measurements yields a value $2.5 \sigma$ larger than the Earth value. This interesting result needs to be further investigated in other comets.

The sensitivity was not sufficient to detect other ${ }^{13} \mathrm{C}$ isotopologues. The most sensitive limit was reached for the ${ }^{13} \mathrm{CH}_{3} \mathrm{OH} \quad\left(5_{+2}-4_{+1} E\right)$ and ${ }^{12} \mathrm{CH}_{3} \mathrm{OH}\left(5_{+2}-4_{+1} E\right)$ lines at 261.113 and $266.838 \mathrm{GHz}$, respectively. The derived lower limit is ${ }^{12} \mathrm{C} /{ }^{13} \mathrm{C}>61$ in comet Lovejoy, compatible with the Earth value.

\section{5. ${ }^{32} \mathrm{~S} /{ }^{34} \mathrm{~S}$ ratio}

The wide $8 \mathrm{GHz}$ frequency coverage of the EMIR receiver at IRAM, allows us to observe both $\mathrm{C}^{32} \mathrm{~S}$ and $\mathrm{C}^{34} \mathrm{~S}$ or $\mathrm{H}_{2}^{32} \mathrm{~S}$ and $\mathrm{H}_{2}^{34} \mathrm{~S}$ lines in the same FTS spectrum since they are less than $4 \mathrm{GHz}$ apart. As a consequence, the isotopic ratios do not depend on any calibration or pointing effects and, since the lines are mostly optically thin, the abundance ratio is very close to the line intensity ratio. The integration time on the $\mathrm{H}_{2} \mathrm{~S}$ lines (either around 168 or $216 \mathrm{GHz}$ ) was not sufficient to yield a significant constraint on the $\mathrm{H}_{2}^{32} \mathrm{~S} / \mathrm{H}_{2}^{34} \mathrm{~S}$ ratio. On the other hand, the $\mathrm{C}^{34} \mathrm{~S}(5-4)$ line at $241016.089 \mathrm{MHz}$ was detected in both comets (Figs. 7 and 8). The accuracy of the ${ }^{32} \mathrm{~S} /{ }^{34} \mathrm{~S}$ ratio in CS is given by the signal-to-noise ratio of the $\mathrm{C}^{34} \mathrm{~S}$ line, and we found ${ }^{32} \mathrm{~S} /{ }^{34} \mathrm{~S}=20 \pm 5$ and $24.7 \pm 3.5$ in comets Lemmon and Lovejoy, respectively. We do not find any significant departure from the Earth value of ${ }^{32} \mathrm{~S} /{ }^{34} \mathrm{~S}=22.5$. The $\mathrm{C}^{33} \mathrm{~S}$ line lies between the $C^{34} S$ and $C^{32} S$ lines. The upper limit for the $C^{33} S(5-4)$ line at $242.913 \mathrm{GHz}$ in comet Lovejoy yields ${ }^{32} \mathrm{~S} /{ }^{33} \mathrm{~S}>50$. This is the first reported estimate of ${ }^{33} \mathrm{~S}$ in a comet, but this is only a lower limit compatible with the Earth value (126.7).

\section{Discussion}

We measured a terrestrial value for the ${ }^{16} \mathrm{O} /{ }^{18} \mathrm{O}$ ratio in water in comet Lovejoy, as was the case in all comets in which this ratio had been measured before (Balsiger et al. 1995; Biver et al. 2007; Bockelée-Morvan et al. 2012, 2015; Altwegg et al. 2015).

The $\mathrm{D} / \mathrm{H}$ and ${ }^{14} \mathrm{~N} /{ }^{15} \mathrm{~N}$ ratios in solar system bodies are of particular importance as they vary from object to object, with the heavier elements enriched in the Earth and small bodies compared to Jupiter or the protosolar values. These ratios trace the various enrichment and fractionation mechanisms that were at play in the proto-planetary nebula. The other isotopic ratios investigated here do not show significant variations in solar system objects within the accuracy of our measurements. Figure 9 shows the ${ }^{14} \mathrm{~N} /{ }^{15} \mathrm{~N}$ versus $\mathrm{D} / \mathrm{H}$ ratios measured in solar system objects, including our new measurements presented here.

\subsection{Earth-like water in comet Lovejoy}

We obtained a measurement or at least a stringent upper limit for the $\mathrm{D} / \mathrm{H}$ ratio in water of two dynamically old Oort cloud comets. We measured the lowest $\mathrm{D} / \mathrm{H}$ ratio in water in a comet so far: $1.4 \pm 0.4 \times 10^{-4}\left(<1.8 \times 10^{-4} ; 5 \sigma\right)$ in Lovejoy, while the corresponding ratio could be four times higher in comet Lemmon. These two D/H measurements are based on the same line in two comets of similar activity. Comet Lemmon was slightly more active but also two times farther away. We do not expect that the excitation mechanism of HDO in the coma of these comets

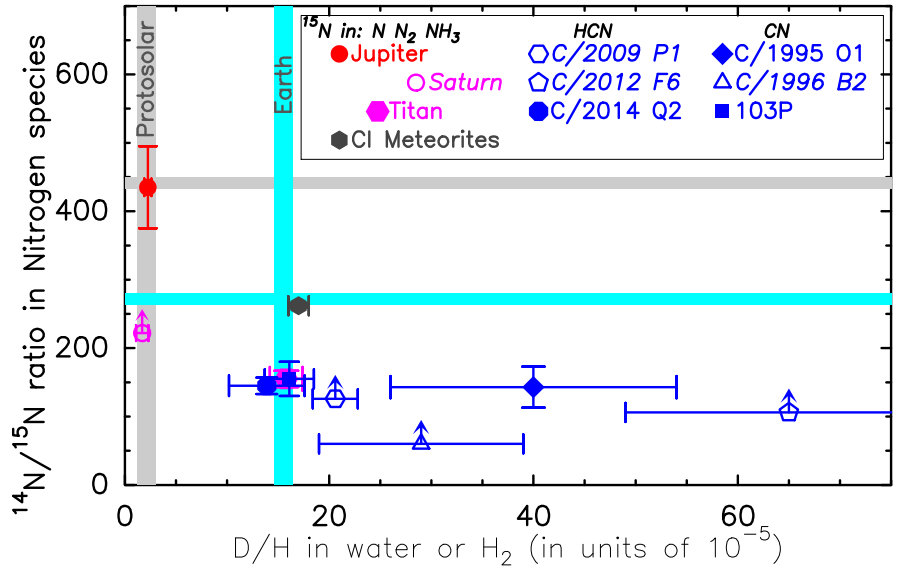

Fig. 9. D/H ratios and ${ }^{14} \mathrm{~N} /{ }^{15} \mathrm{~N}$ ratios in solar system objects, compared to the protosolar (gray bands) and Earth (blue bands) values (Robert et al. 2000; Marty et al. 2011). Jupiter and Saturn values are from Marty et al. (2011), Füri \& Marty (2015), and Fletcher et al. (2014); Titan values from Abbas et al. (2010), Niemann et al. (2010), and Mandt et al. (2009, 2014); meteorites from Waite et al. (2009) and Kerridge (1985); and comet values from Bockelée-Morvan et al. (1998), Meier et al. (1998), Crovisier et al. (2004a), Hartogh et al. (2011), Bockelée-Morvan et al. (2012), Bockelée-Morvan et al. (2008), Hutsemékers et al. (2009), Meech et al. (2011), and this paper. The symbols corresponding to each source are given in the enclosed legend box. They are ordered according to the species in which the ${ }^{14} \mathrm{~N} /{ }^{15} \mathrm{~N}$ was measured from left to right: atomic nitrogen, $\mathrm{N}_{2}$ (as for Earth), ammonia, HCN, and CN. Empty symbols with names in italics are for lower limits on the ${ }^{14} \mathrm{~N} /{ }^{15} \mathrm{~N}$.

can yield a factor of four difference in the derived production rates. So the observed diversity in the $\mathrm{D} / \mathrm{H}$ ratio can be real and would suggest that these two comets, although they come from the same current reservoir, were formed in different places or at different times in the young solar system. In either case, this brings additional proof that comet dynamical origin does not imply a specific formation region in the disk. Previous studies (Hartogh et al. 2011; Lis et al. 2013; Bockelée-Morvan et al. 2012; Altwegg et al. 2015) have shown a growing diversity in the measured values of the $\mathrm{D} / \mathrm{H}$ ratio in cometary water, and especially variations by more than a factor of 3 among Jupiter family comets, which are thought to originate from the Kuiper belt. Now we find that a similar range of values is present among Oort cloud comets. This is in line with the latest models (Brasser \& Morbidelli 2013), which suggest that all comets were formed in the same extended massive original Kuiper Belt beyond the giant planets and were later scattered to the two current reservoirs, the scattered Kuiper disk and the Oort cloud. The diversity in deuterium enrichment would occur because the presolar cloud was initially enriched in HDO (higher $\mathrm{D} / \mathrm{H}$ in water than in $\mathrm{H}_{2}$ : protosolar $\mathrm{D} / \mathrm{H}$ value in $\mathrm{H}_{2}$ is $2 \times 10^{-5}$, Fig. 9), but the inner warmer parts of the proto-planetary nebula lost more of their initial enrichment in deuterated water.

\section{2. ${ }^{14} \mathrm{~N} /{ }^{15} \mathrm{~N}$ in comets}

Measurements of ${ }^{14} \mathrm{~N} /{ }^{15} \mathrm{~N}$ in comets are relatively scarce. Although the ${ }^{14} \mathrm{~N} /{ }^{15} \mathrm{~N}$ ratio is $5-20$ times lower than the $\mathrm{H}_{2}^{16} \mathrm{O} / \mathrm{HDO}$ ratio, the nitrogen bearing molecules in cometary comae are less than $1 \%$ in abundance relative to water. So the detection of ${ }^{15} \mathrm{~N}$ isotopologues requires very active comets. The most sensitive technique is optical high resolution spectroscopy, which has provided several detections of $\mathrm{C}^{15} \mathrm{~N}$ (Manfroid et al. 2005, 2009; Hutsemékers et al. 2009) and recently detections 
of ${ }^{15} \mathrm{NH}_{2}$ (Rousselot et al. 2014; Shinnaka et al. 2015), but this technique only gives access to daughter species. The compounds $\mathrm{N}_{2}$ and $\mathrm{NH}_{3}$ are not very abundant (Rubin et al. 2015; Biver et al. 2012) and do not have strong lines observable from the ground, nor do their ${ }^{15} \mathrm{~N}$ isotopologues. Only $\mathrm{HCN}$ is easily detectable in the radio and infrared. We report here the third clear $(S / N>10)$ detection of $\mathrm{HC}^{15} \mathrm{~N}$ in a comet after its detection in comets Hale-Bopp and 17P/Holmes (Bockelée-Morvan et al. 2008).

We measure the same enrichment in ${ }^{15} \mathrm{~N}$ in $\mathrm{HCN}$ in comet Lovejoy as in other comets, in spite of their different dynamical origins (Bockelée-Morvan et al. 2008). The same enrichment was also found in $\mathrm{CN}$ in many other comets (Hutsemékers et al. 2009). This is a factor of two enrichment in ${ }^{15} \mathrm{~N}$ in comparison to the Earth atmospheric value (272) and a factor of three in comparison to the proto-planetary value (441, Marty et al. 2011) (Fig. 9). The enrichment is similar to that found in $\mathrm{NH}_{2}$ (Rousselot et al. 2014; Shinnaka et al. 2015), thought to be mostly produced by the photo-dissociation of $\mathrm{NH}_{3}$, the main volatile carrier of cometary nitrogen (Biver et al. 2012).

Correspondingly low ${ }^{14} \mathrm{~N} /{ }^{15} \mathrm{~N}$ ratios are also detected in carbonaceous interplanetary dust particles (IDPs) (Messenger 2000; Floss et al. 2004). These large enrichments with respect to solar or terrestrial values can be explained by interstellar chemistry theories involving ion-molecule ${ }^{15} \mathrm{~N}$ fractionation at $10 \mathrm{~K}$ (e.g., Wirström et al. 2012). Recently, significant nitrogen fractionation has been measured in dark cloud cores with ratios as low as 150 for nitriles (Milam et al. 2015). Thus, the similarity of the ${ }^{14} \mathrm{~N} /{ }^{15} \mathrm{~N}$ ratios found in comets and IDPs strengthens a putative link to interstellar chemistry as the origin of isotopically anomalous organic particles in comets.

Nevertheless, our observations confirms that the trend of a twofold enrichment in ${ }^{15} \mathrm{~N}$ compared to Earth observed in $\mathrm{C}^{15} \mathrm{~N}$ is also present in $\mathrm{HCN}$. A consequence concerning the debate of the origin of $\mathrm{CN}$ in cometary coma is that we cannot exclude $\mathrm{HCN}$ as the sole parent of $\mathrm{CN}$ on the basis of different ${ }^{14} \mathrm{~N} /{ }^{15} \mathrm{~N}$ ratios.

\section{Conclusions}

Chemical diversity is observed in the population of Oort Cloud comets, with abundances varying by up to a factor of ten for several species. The origin of this diversity is unclear and might reflect comet formation at different places or times in the early solar system.

The observations presented here provide further evidence that diversity is present in the enrichment in deuterium in cometary water with respect to the protosolar value $\left(\mathrm{HD} / \mathrm{H}_{2}\right)$, both in Jupiter family and Oort cloud comets, in line with the latest scenarios of comet origins (Brasser \& Morbidelli 2013). On the one hand, we found Earth-like $\mathrm{D} / \mathrm{H},{ }^{16} \mathrm{O} /{ }^{18} \mathrm{O},{ }^{12} \mathrm{C} /{ }^{13} \mathrm{C}$, and ${ }^{32} \mathrm{~S} /{ }^{34} \mathrm{~S}$ ratios in comet $\mathrm{C} / 2014 \mathrm{Q} 2$ (Lovejoy), strengthening the role that some comets may have played in supplying material to the young Earth, especially complex organic molecules (Biver et al. 2015). On the other hand we confirm the trend of finding a systematic twofold enrichment in ${ }^{15} \mathrm{~N}$ in cometary $\mathrm{HCN}$ relative to its abundance in Earth $\mathrm{N}_{2}$, whose origin is puzzling.

We were also able to obtain in comet C/2014 Q2 sensitive limits, some of the best obtained so far with remote observations, on isotopic ratios in other molecules such as $\mathrm{D} / \mathrm{H}$ in $\mathrm{H}_{2} \mathrm{~S}, \mathrm{H}_{2} \mathrm{CO}$, or $\mathrm{C}^{32} \mathrm{~S} / \mathrm{C}^{33} \mathrm{~S}$.
Acknowledgements. The IRAM observations were conducted under the target of opportunity proposal D04-14 and regular proposal 128-14 and we gratefully acknowledge the support from the IRAM director for awarding us discretionary time and the IRAM staff for its support and for scheduling the observations on short notice. This research has been supported by the Programme national de planétologie de l'Institut des sciences de l'univers (INSU). S.N.M. acknowledges the NASA Planetary Astronomy program for support.

\section{References}

Abbas, M. M., Kandadi, H., LeClair, A., et al. 2010, ApJ, 708, 342 Altwegg, K., \& Bockelée-Morvan, D. 2003, Space Sci. Rev., 106, 139 Altwegg, K., Balsiger, H., Bar-Nun, A., et al. 2015, Science, 347, 1261952 Balsiger, H., Altwegg, K., \& Geiss, J. 1995, J. Geophys. Res., 100, 5827 Biver, N., Bockelée-Morvan, D., Crovisier, J., et al. 2000, AJ, 120, 1554 Biver, N., Bockelée-Morvan, D., Crovisier, J., et al. 2006, A\&A, 449, 1255 Biver, N., Bockelée-Morvan, D., Crovisier, J., et al. 2007, Planet. Space Sci., 55, 1058

Biver, N., Crovisier, J., Bockelée-Morvan, D., et al. 2012, A\&A, 539, A68

Biver, N., Bockelée-Morvan, D., Debout, V., et al. 2014, A\&A, 566, L5

Biver, N., Bockelée-Morvan, D., Moreno, R., et al. 2015, Sci. Adv., 1, e1500863

Bockelée-Morvan, D., Gautier, D., Lis, D. C., et al. 1998, Icarus, 133, 147 Bockelée-Morvan, D., Lis, D. C., Wink, J. E., et al. 2000, A\&A, 353, 1101 Bockelée-Morvan, D., Biver, N., Jehin, E., et al. 2008, ApJ, 679, L49 Bockelée-Morvan, D., Biver, N., Swinyard, B., et al. 2012, A\&A, 544, L15 Bockelée-Morvan, D., Calmonte, U., Charnley, S., et al. 2015, Space Sci. Rev., 197, 47

Brasser, R., \& Morbidelli, A. 2013, Icarus, 225, 40

Carter, M., Lazareff, R., Maier, D., et al. 2012, A\&A, 538, A89

Combi, M. R., Bertaux, J.-L., Quémerais, E., et al. 2014, AJ, 147, 126

Crovisier, J. 1994, J. Geophys. Res., 99, 3777

Crovisier, J., Bockelée-Morvan, D., Biver, N., et al. 2004a, A\&A, 418, L35

Crovisier, J., Bockelée-Morvan, D., Colom, P., et al. 2004b, A\&A, 418, 1141 Fletcher, L. N., Greathouse, T. K., Orton, G. S., et al. 2014, Icarus, 238, 170 Floss, C., Stadermann, F. J., Bradley, J., et al. 2004, Science, 303, 1355 Frisk, U., Hagström, M., Ala-Laurinaho, J., et al. 2003, A\&A, 402, L27 Füri, E., \& Marty B. 2015, Nature Geoscience, 8, 515

Gérard, E., Crovisier, J., Colom, P., et al. 1998, Planet. Space Sci., 46, 569 Hartogh, P., Lis, D. C., Bockelée-Morvan, D., et al. 2011, Nature, 478, 218 Hutsemékers, D., Manfroid, J., Jehin, E., \& Arpigny, C. 2009, Icarus, 204, 346

Jewitt, D., Matthews, H. E., Owen, T., \& Meier, R. 1997, Science, 278, 90 Kerridge, J. F. 1985, Geochim. Cosmochim. Acta, 49, 1707

Lis, D. C., Biver, N., Bockelée-Morvan, D., et al. 2013, ApJ, 774, L3

Mandt, K. E., Waite, J. H., Lewis, W., et al. 2009, Planet. Space Sci., 57, 1917

Mandt, K. E., Mousis, O., Lunine, J., \& Gautier, D. 2014, ApJ, 788, L24

Manfroid, J., Jehin, E., Hutsemékers, D., et al. 2005, A\&A, 432, L5

Manfroid, J., Jehin, E., Hutsemékers, D., et al. 2009, A\&A, 503, 613

Marty, B., Chaussidon, M., Wiens, R. C., Jurewicz, A. J. G., \& Burnett, D. S. 2011, Science, 332, 1533

Meech, K. J., A'Hearn, M. F., Adams, J. A., et al. 2011, ApJ, 734, L1

Meier, R., Owen, T. C., Matthews, H. E., et al. 1998, Science, 279, 842

Messenger, S. 2000, Nature, 404, 968

Milam, S. N., Adande, G., Cordiner, M. A., Wirstrom, E., \& Charnley, S. B. 2015, LPI Contribution, 1832, 1934

Müller, H. S. P., Schlöder, F., Stutzki J., \& Winnewisser, G. 2005, J. Mol. Struct., 742,215

Niemann, H. B., Atreya, S. K., Demick, J. E., et al. 2010, J. Geophys. Res., 115, E12, E12006

O'Brien, D. P., Walsh, K. J., Morbidelli, A., Raymond, S. N., \& Mandell, A. M. 2014, Icarus, 239, 74

Paganini, L., DiSanti, M. A., Mumma, M. J., et al. 2014, AJ, 147, 15

Pickett, H. M., Poynter, R. L., Cohen, E. A., et al. 1998, J. Quant. Spectr. Rad. Transf., 60, 883

Robert, F., Gautier, D., \& Dubrulle, B. 2000, Space Sci. Rev., 92, 201

Rousselot, P., Pirali, O., Jehin, E., et al. 2014, ApJ, 780, L17

Rubin, M., Altwegg, K., Balsiger, H., et al. 2015, Science, 348, 232

Shinnaka, Y., Kawakita, H., Kobayashi, H., et al. 2015, ApJ, 782, L16

Waite, J. H., Jr., Lewis, W. S., Magee, B. A., et al. 2009, Nature, 460, 487

Wirström, E. S., Charnley, S. B., Cordiner, M. A., \& Milam, S. N. 2012, ApJ, 757, L11

Zakharov, V., Bockelée-Morvan, D., Biver, N., Crovisier, J., \& Lecacheux, A. 2007, A\&A, 473, 303 


\section{Appendix A: Additional tables}

Table A.1. Circumstances of IRAM observations and reference parameters.

\begin{tabular}{|c|c|c|c|c|c|c|c|c|}
\hline $\begin{array}{l}\text { UT date } \\
\text { (yyyy/mm/dd.d-dd.d) }\end{array}$ & $\begin{array}{l}\left\langle r_{\mathrm{h}}\right\rangle \\
(\mathrm{AU})\end{array}$ & $\begin{array}{l}\langle\Delta\rangle \\
(\mathrm{AU})\end{array}$ & $\begin{array}{l}\text { Integ. time } \\
\quad(\min )^{a}\end{array}$ & $\begin{array}{l}\text { Freq. range } \\
(\mathrm{GHz})\end{array}$ & $\begin{array}{c}v_{\exp } \\
\left(\mathrm{km} \mathrm{s}^{-1}\right)\end{array}$ & $\begin{array}{l}T_{\text {kin }} \\
(\mathrm{K})\end{array}$ & $\begin{array}{c}Q_{\mathrm{H}_{2} \mathrm{O}}{ }^{b, c} \\
\left(\text { molec s s}^{-1}\right)\end{array}$ & $\begin{array}{c}Q_{\mathrm{CH}_{3} \mathrm{OH}} \\
\left(\mathrm{molec} \mathrm{s}^{-1}\right)\end{array}$ \\
\hline \multicolumn{9}{|c|}{ Comet C/2012 F6 (Lemmon): } \\
\hline $2013 / 03 / 14.52-14.55$ & 0.758 & 1.348 & 26 & $249-256,264-272$ & 1.10 & 110 & $\sim 10 \times 10^{29}$ & $2.1 \pm 0.1 \times 10^{28}$ \\
\hline 2013/03/14.57-14.59 & 0.758 & 1.349 & 20 & $240-248,256-264$ & 1.10 & 110 & $\sim 10 \times 10^{29}$ & $2.3 \pm 0.1 \times 10^{28}$ \\
\hline $2013 / 03 / 15.52-15.57$ & 0.753 & 1.362 & 21 & $249-256,264-272$ & 1.10 & 110 & $\sim 10 \times 10^{29}$ & $1.7 \pm 0.2 \times 10^{28}$ \\
\hline $2013 / 03 / 15.58-15.59$ & 0.753 & 1.362 & 14 & $210-218,226-234$ & 1.10 & 110 & $\sim 10 \times 10^{29}$ & \\
\hline $2013 / 03 / 18.53-18.55$ & 0.741 & 1.400 & 17 & $249-256,264-272$ & 1.10 & 110 & $\sim 10 \times 10^{29}$ & $1.6 \pm 0.2 \times 10^{28}$ \\
\hline 2013/03/18.55-18.59 & 0.741 & 1.400 & 20 & $240-248,256-264$ & 1.10 & 110 & $\sim 10 \times 10^{29}$ & $2.1 \pm 0.1 \times 10^{28}$ \\
\hline 2013/04/06.40-06.51 & 0.776 & 1.592 & 69 & $249-256,264-272$ & 1.00 & 100 & $\sim 9 \times 10^{29}$ & $1.5 \pm 0.1 \times 10^{28}$ \\
\hline $2013 / 04 / 06.53-06.60$ & 0.776 & 1.592 & 54 & $240-248,256-264$ & 1.00 & 100 & $\sim 9 \times 10^{29}$ & $1.4 \pm 0.1 \times 10^{28}$ \\
\hline 2013/04/07.49-07.52 & 0.783 & 1.600 & 20 & $249-256,264-272$ & 1.00 & 100 & $\sim 9 \times 10^{29}$ & $1.6 \pm 0.2 \times 10^{28}$ \\
\hline $2013 / 04 / 07.53-07.59$ & 0.783 & 1.600 & 58 & $210-218,226-234$ & 1.00 & 100 & $\sim 9 \times 10^{29}$ & $1.2 \pm 0.4 \times 10^{28}$ \\
\hline $2013 / 04 / 08.43-08.50$ & 0.790 & 1.606 & 62 & $85-93,166-170$ & 1.00 & 100 & $\sim 9 \times 10^{29}$ & $1.5 \pm 0.1 \times 10^{28}$ \\
\hline $2013 / 04 / 08.51-08.54$ & 0.790 & 1.606 & 28 & $249-256,264-272$ & 1.00 & 100 & $\sim 9 \times 10^{29}$ & $1.5 \pm 0.1 \times 10^{28}$ \\
\hline 2013/04/08.55-08.59 & 0.791 & 1.607 & 36 & $218-226,234-242$ & 1.00 & 100 & $\sim 9 \times 10^{29}$ & $1.7 \pm 0.2 \times 10^{28}$ \\
\hline \multicolumn{9}{|c|}{ Comet C/2014 Q2 (Lovejoy): } \\
\hline 2015/01/13.75-13.77 & 1.314 & 0.496 & 1 & 249 & 0.80 & 73 & $5 \times 10^{29}$ & $1.17 \pm 0.03 \times 10^{28}$ \\
\hline 2015/01/13.79-13.84 & 1.314 & 0.497 & 29 & $210-218,22$ & 0.80 & 73 & & $1.25 \pm 0.07 \times 10^{28}$ \\
\hline $2015 / 01 / 13.85-13.88$ & 1.313 & 0.497 & 29 & $240-248,256-264$ & 0.80 & 73 & $5 \times 10^{29}$ & $1.25 \pm 0.02 \times 10^{28}$ \\
\hline $2015 / 01 / 15.82-15.83$ & 1.308 & 0.516 & 13 & $249-256,264-272$ & 0.80 & 73 & $5 \times 10^{29}$ & $1.18 \pm 0.04 \times 10^{28}$ \\
\hline $2015 / 01 / 15.85-15.96$ & 1.308 & 0.516 & 105 & $240-248,256-264$ & 0.80 & 73 & $5 \times 10^{29}$ & $1.42 \pm 0.02 \times 10^{28}$ \\
\hline 2015/01/16.76-16.78 & 1.306 & 0.526 & 14 & $249-256,264-272$ & 0.80 & 73 & $5 \times 10^{29}$ & $1.14 \pm 0.01 \times 10^{28}$ \\
\hline $2015 / 01 / 16.81-16.95$ & 1.306 & 0.527 & 120 & $240-248,256-264$ & 0.80 & 73 & $5 \times 10^{29}$ & $1.17 \pm 0.02 \times 10^{28}$ \\
\hline $2015 / 01 / 23.72-23.75$ & 1.294 & 0.624 & 36 & $240-248,256-264$ & 0.80 & 73 & $6 \times 10^{29}$ & $1.48 \pm 0.03 \times 10^{28}$ \\
\hline $2015 / 01 / 24.73-24.75$ & 1.293 & 0.641 & 14 & $226-234,241-249$ & 0.80 & 73 & $6 \times 10^{29}$ & $1.27 \pm 0.06 \times 10^{28}$ \\
\hline $2015 / 01 / 25.71-25.75$ & 1.292 & 0.658 & 42 & $210-218,225-233$ & 0.80 & 73 & $6 \times 10^{29}$ & $1.00 \pm 0.04 \times 10^{28}$ \\
\hline $2015 / 01 / 26.74-26.75$ & 1.291 & 0.675 & 6 & $85-93,101-109$ & 0.80 & 73 & $7 \times 10^{29}$ & $1.99 \pm 0.20 \times 10^{28}$ \\
\hline
\end{tabular}

Notes. ${ }^{(a)}$ On nucleus pointings only. ${ }^{(b)}$ For comet Lemmon, Combi et al. (2014) provide $Q_{\mathrm{H}_{2} \mathrm{O}}$ values in the range $7-12 \times 10^{29}$ molec s ${ }^{-1}$ during this period. Contemporaneous SWAN measurements are slightly lower than quoted here, but they were not time-deconvolved and the average values measured by SWAN a few days later are within $10 \%$ of those given here. Given our measured $Q_{\mathrm{CH}_{3} \mathrm{OH}}\left(\mathrm{Col}\right.$. 9), $Q_{\mathrm{H}_{2} \mathrm{O}}$ are also in agreement with the measurement of Paganini et al. (2014) as they yield the same $Q_{\mathrm{CH}_{3} \mathrm{OH}} / Q_{\mathrm{H}_{2} \mathrm{O}}$ ratio. Nançay observations are also compatible with these $Q_{\mathrm{H}_{2} \mathrm{O}}$ although the quenching of the $\mathrm{OH}$ maser is poorly constrained and the uncertainty on $Q_{\mathrm{OH}}$ is very large. ${ }^{(c)}$ For comet Lovejoy, $Q_{\mathrm{H}_{2} \mathrm{O}}$ are based on Odin and Nançay data (see text and Biver et al. 2015). 
Table A.2. Line intensities from IRAM observations and production rates.

\begin{tabular}{|c|c|c|c|c|c|}
\hline $\begin{array}{l}\text { Date } \\
\text { [yyyy/mm/dd.d - dd.d] }\end{array}$ & Molecule & Transition & $\begin{array}{c}\text { Frequency } \\
{[\mathrm{MHz}]}\end{array}$ & $\begin{array}{c}\text { Intensity } \\
{\left[\mathrm{mK} \mathrm{km} \mathrm{s}^{-1}\right]}\end{array}$ & $\begin{array}{c}\text { Total production rate } \\
{\left[10^{26} \text { molec. } \mathrm{s}^{-1}\right]}\end{array}$ \\
\hline \multicolumn{6}{|c|}{ Comet C/2012 F6 (Lemmon) March-April 2013} \\
\hline 2013/03/14.5-18.6 & $\mathrm{HCN}$ & $3-2$ & 265886.432 & $6055 \pm 36$ & $15.3 \pm 2.1^{a}$ \\
\hline $2013 / 04 / 06.46$ & $\mathrm{HCN}$ & $3-2$ & & $5966 \pm 50$ & $13.1 \pm 0.8^{a}$ \\
\hline 2013/03/14.5-18.6 & $\mathrm{H}^{13} \mathrm{CN}$ & $3-2$ & 259011.798 & $65 \pm 44$ & $<0.28$ \\
\hline $2013 / 04 / 06.56$ & $\mathrm{H}^{13} \mathrm{CN}$ & $3-2$ & & $43 \pm 32$ & $<0.20$ \\
\hline 2013/03/14.5-37.6 & $\mathrm{H}^{13} \mathrm{CN}$ & $3-2$ & & $51 \pm 26$ & $0.12 \pm 0.06$ \\
\hline 2013/03/14.5-18.6 & $\mathrm{HC}^{15} \mathrm{~N}$ & $3-2$ & 258156.996 & $108 \pm 36$ & $<0.25$ \\
\hline $2013 / 04 / 06.46$ & $\mathrm{HC}^{15} \mathrm{~N}$ & $3-2$ & & $11 \pm 22$ & $<0.14$ \\
\hline $2013 / 03 / 14.5-37.6$ & $\mathrm{HC}^{15} \mathrm{~N}$ & $3-2$ & & $40 \pm 19$ & $0.09 \pm 0.04$ \\
\hline 2013/03/15.6-38.6 & $\mathrm{DCN}$ & $3-2$ & 217238.538 & $<133$ & $<0.52$ \\
\hline $2013 / 04 / 08.47$ & $\mathrm{H}_{2} \mathrm{~S}$ & $1_{10}-1_{01}$ & 168762.762 & $234 \pm 36$ & $77 \pm 13^{a}$ \\
\hline $2013 / 04 / 08.47$ & $\mathrm{H}_{2}^{34} \mathrm{~S}$ & $1_{10}-1_{01}$ & 167910.516 & $<66$ & $<21$ \\
\hline 2013/03/14.6-18.6 & $\stackrel{2}{\mathrm{~S}}$ & $5-4$ & 244935.557 & $1477 \pm 38$ & $14.7 \pm 0.6^{a}$ \\
\hline $2013 / 04 / 06.56$ & $\mathrm{CS}$ & $5-4$ & & $1019 \pm 25$ & $9.5 \pm 0.2$ \\
\hline 2013/03/14.6-18.6 & $C^{34} S$ & $5-4$ & 241016.089 & $50 \pm 31$ & $0.51 \pm 0.31$ \\
\hline 2013/04/06.56 & $C^{34} S$ & $5-4$ & & $58 \pm 16$ & $0.57 \pm 0.16$ \\
\hline $2013 / 03 / 15.6-38.6$ & $C^{34} S$ & $5-4$ & & $53 \pm 13$ & $0.54 \pm 0.13$ \\
\hline $2013 / 03 / 14.6-18.6$ & HDO & $2_{11}-2_{12}$ & 241561.550 & $88 \pm 29$ & $21 \pm 7$ \\
\hline 2013/04/06.56 & HDO & $22_{11}-2_{12}$ & & $44 \pm 19$ & $12 \pm 4$ \\
\hline 2013/03/14.6-37.6 & HDO & $2_{11}-2_{12}$ & & $54 \pm 14$ & $13 \pm 3$ \\
\hline \multicolumn{6}{|c|}{ Comet C/2014 Q2 (Lovejoy) 13-25 January 2015} \\
\hline 2015/01/13.7-16.8 & $\mathrm{HCN}$ & $3-2$ & 265886.432 & $10848 \pm 39$ & $4.9 \pm 0.2^{a}$ \\
\hline $2015 / 01 / 13.7-16.8$ & $\mathrm{H}^{13} \mathrm{CN}$ & $3-2$ & 259011.798 & $114 \pm 13$ & $0.049 \pm 0.006$ \\
\hline $2015 / 01 / 23.73$ & $\mathrm{H}^{13} \mathrm{CN}$ & $3-2$ & & $86 \pm 18$ & $0.043 \pm 0.009$ \\
\hline $2015 / 01 / 13.7-23.7$ & $\mathrm{H}^{13} \mathrm{CN}$ & $3-2$ & & $100 \pm 12$ & $0.046 \pm 0.006$ \\
\hline 2015/01/13.7-16.8 & $\mathrm{HC}^{15} \mathrm{~N}$ & $3-2$ & 258156.996 & $86 \pm 9$ & $0.037 \pm 0.004$ \\
\hline $2015 / 01 / 23.73$ & $\mathrm{HC}^{15} \mathrm{~N}$ & $3-2$ & & $85 \pm 13$ & $0.043 \pm 0.007$ \\
\hline $2015 / 01 / 13.7-23.7$ & $\mathrm{HC}^{15} \mathrm{~N}$ & $3-2$ & & $83 \pm 7$ & $0.039 \pm 0.003$ \\
\hline $2015 / 01 / 13.7-24.7$ & $\mathrm{DCN}$ & $3-2$ & 217238.538 & $<39$ & $<0.031$ \\
\hline $2015 / 01 / 13.7-16.8$ & $\mathrm{CH}_{3} \mathrm{OH}$ & $5_{2}-4_{1} \mathrm{E}$ & 266838.123 & $1345 \pm 24$ & $117 \pm 3^{a}$ \\
\hline $2015 / 01 / 13.7-23.7$ & ${ }^{13} \mathrm{CH}_{3} \mathrm{OH}$ & $5_{2}-4_{1} \mathrm{E}$ & 263113.343 & $<23$ & $<2.4$ \\
\hline $2015 / 01 / 13.7-25.7$ & $\mathrm{H}_{2} \mathrm{CO}$ & $3_{13}-212$ & 211211.469 & $978 \pm 11$ & $18 \pm 1^{a}$ \\
\hline $2015 / 01 / 13.7-25.7$ & $\mathrm{H}_{2} \mathrm{CO}$ & $3_{12}-2$ & 225697.772 & $1181 \pm 17$ & $18 \pm 1^{a}$ \\
\hline $2015 / 01 / 13.7-23.7$ & $\mathrm{HDCO}$ & $4_{14}-3_{13}$ & 246924.600 & $<18$ & $<0.38$ \\
\hline $2015 / 01 / 13.7-23.7$ & $\mathrm{HDCO}$ & $4_{04}-3_{03}$ & 256585.531 & $<21$ & $<0.36$ \\
\hline $2015 / 01 / 13.8-25.7$ & $\mathrm{H}_{2} \mathrm{~S}$ & $2_{20}-2_{11}$ & 216710.437 & $227 \pm 12$ & $17.3 \pm 0.9^{a}$ \\
\hline 2015/01/13.8-25.7 & $\mathrm{H}_{2}^{34} \mathrm{~S}$ & $2_{20}-2_{11}$ & 214376.924 & $16 \pm 11$ & $<2.6$ \\
\hline 2015/01/13.8-23.7 & HDS & $22_{11}-2_{02}$ & 257781.410 & $<21$ & $<0.6$ \\
\hline 2015/01/13.8-16.9 & $\mathrm{CS}$ & $5-4$ & 244935.557 & $1049 \pm 10$ & $2.14 \pm 0.02^{a}$ \\
\hline $2015 / 01 / 23.7-24.7$ & $\mathrm{CS}$ & $5-4$ & & $1089 \pm 10$ & $2.51 \pm 0.02^{a}$ \\
\hline $2015 / 01 / 13.8-23.7$ & $\mathrm{CS}$ & $5-4$ & & $1076 \pm 7$ & $2.30 \pm 0.02^{a}$ \\
\hline 2015/01/13.8-16.9 & $C^{34} S$ & $5-4$ & 241016.089 & $37 \pm 9$ & $0.077 \pm 0.019$ \\
\hline $2015 / 01 / 23.73$ & $C^{34} S$ & $5-4$ & & $53 \pm 13$ & $0.126 \pm 0.031$ \\
\hline $2015 / 01 / 13.8-23.7$ & $C^{34} S$ & $5-4$ & & $42 \pm 6$ & $0.093 \pm 0.013$ \\
\hline $2015 / 01 / 13.8-23.7$ & $C^{33} S$ & $5-4$ & 242913.610 & $<21$ & $<0.046$ \\
\hline 2015/01/13.8-16.9 & $\mathrm{HDO}$ & $2_{11}-2_{12}$ & 241561.550 & $31 \pm 8$ & $1.8 \pm 0.4$ \\
\hline $2015 / 01 / 23.7-24.7$ & HDO & $22_{11}-2_{12}$ & & $23 \pm 11$ & $1.6 \pm 0.7$ \\
\hline 2015/01/13.8-24.7 & HDO & $22_{11}-2_{12}$ & & $25 \pm 7$ & $1.5 \pm 0.4$ \\
\hline
\end{tabular}

Notes. ${ }^{(a)}$ Average production rate for the period also taking into account measurements at 5 to $20^{\prime \prime}$ offsets. For formaldehyde the offset positions were used to constrain the contribution of the distributed source: $80 \%$ with a scale-length of $10000 \mathrm{~km}$. 